\title{
Selective Effects of Dopamine Depletion and L-DOPA Therapy on Learning-Related Firing Dynamics of Striatal Neurons
}

\author{
Ledia F. Hernandez, Yasuo Kubota, Dan Hu, Mark W. Howe, Nuné Lemaire, and Ann M. Graybiel \\ McGovern Institute for Brain Research and Department of Brain and Cognitive Sciences, Massachusetts Institute of Technology, Cambridge, Massachusetts
} 02139

\begin{abstract}
Despite evidence that dopamine neurotransmission in the striatum is critical for learning as well as for movement control, little is yet known about how the learning-related dynamics of striatal activity are affected by dopamine depletion, a condition faced in Parkinson's disease. We made localized intrastriatal 6-hydroxydopamine lesions in rats and recorded within the dopamine-depleted sensorimotor striatal zone and its contralateral correspondent as the animals learned a conditional maze task. Rather than producing global, nonspecific elevations in firing rate across the task, the dopamine depletion altered striatal projection neuron activity and fast-spiking interneuron activity selectively, with sharply task-specific and cell type-specific effects, and often, with learning-stage selective effects as well. Striatal projection neurons with strong responses during the maze runs had especially elevated responsiveness during the maze runs. Projection neurons that, instead, fired most strongly before maze running showed elevated pre-start firing rates, but not during maze running, as learning progressed. The intrastriatal dopamine depletion severely affected the learning-related patterning of fast-spiking interneuron ensembles, especially during maze running and after extended training. Remarkably, L-DOPA treatment almost entirely reversed the depletion-induced elevations in pre-run firing of the projection neurons, and elevated their responses around start and end of maze runs. By contrast, L-DOPA failed to normalize fast-spiking interneuron activity. Thus the effects of striatal dopamine depletion and restoration on striatal activity are highly dependent not only on cell type, as previously shown, but also on the behavioral activity called for and the state of behavioral learning achieved.
\end{abstract}

\section{Introduction}

Decades of work have identified changes in the physiology of striatum that likely underlie the movement disorders in Parkinson's disease (Mallet et al., 2006; Brown, 2007; Gerfen and Surmeier, 2011; Picconi et al., 2012). Many types of neurons in the striatum are affected by dopamine depletion, including medium spiny projection neurons (MSNs) (Ingham et al., 1989; Chen et al., 2001; Day et al., 2006), tonically active cholinergic interneurons (TANs), and fast-spiking parvalbumin-containing interneurons (FSIs) (Aosaki et al., 1994b; Salin et al., 2009). Moreover, in vitro evidence suggests that the movementreducing indirect pathway and FSIs related to it are selectively affected (Gittis et al., 2011), a pattern that could lead to disorders of movement control. Further, striking changes occur in the

\footnotetext{
Received July 27, 2012; revised Jan. 7, 2013; accepted Jan. 12, 2013.

Author contributions: L.F.H., Y.K., and A.M.G. designed research; L.F.H. and D.H. performed research; L.F.H., Y.K., D.H., M.W.H., N.L., and A.M.G. analyzed data; L.F.H., Y.K., M.W.H., N.L., and A.M.G. wrote the paper.

This work was funded by National Institutes of Health-National Institute of Neurological Disorders and Stroke P50 NS-38372, National Parkinson Foundation and Stanley H. and Sheila G. Sydney Fund to A.M.G., and Parkinson Disease Foundation Fellowship and Fulbright Fellowship to L.F.H. We thank Andrew McCool, Christine KellerMcGandy, Henry Hall, and Alex McWhinnie for their help.

The authors declare no competing financial interests.

Correspondence should be addressed to Ann M. Graybiel, Massachusetts Institute of Technology, 46-6133, 43 Vassar Street, Cambridge, MA 02139. E-mail: graybiel@mit.edu.

DOI:10.1523/JNEUROSCI.3746-12.2013

Copyright $\odot 2013$ the authors $\quad 0270-6474 / 13 / 334782-14 \$ 15.00 / 0$
}

learning-related activity of TANs in the dopamine-depleted sensorimotor striatum of macaque monkeys (Aosaki et al., 1994a; Apicella, 2007). These changes in the basal ganglia have major consequences for neocortical and other systems, and the striatal loss of dopamine in Parkinson's disease is accompanied by neurodegeneration in other regions (Braak and Braak, 2000; Henderson et al., 2000). Thus the consequences of dopamine depletion are broadly distributed.

Even with these advances, it remains difficult to answer questions such as what is responsible for the particular difficulty that Parkinson's patients have with initiating and terminating sequences of movements, how different striatal populations are affected during task performance, or what changes in population-level activity lie behind the gradually increasing difficulties that occur in procedural learning as the effects of dopamine depletion increase (Cools et al., 2001; Cameron et al., 2010).

Here, we used a local unilateral striatal dopamine depletion model of Parkinson's disease to examine the dynamics of neuronal activity in the dopamine-depleted striatum as rats learned to perform natural navigational sequences. We chose a T-maze task (Barnes et al., 2005) to determine how the depletion affected neuronal activity at key behavioral points: as the animals initiated movements in response to a start cue, made decisions in response to instruction cues, and stopped running to consume the reward. Because the small intrastriatal dopamine depletions did not prevent the animals from learning and performing the maze task, we 
could capitalize on earlier findings demonstrating that as normal rats learn such simple tasks, the activity of neuronal ensembles in the sensorimotor striatum changes to yield eventually taskbracketing ensemble activity emphasizing the beginning and end of the maze runs (Jog et al., 1999; Barnes et al., 2005; Kubota et al., 2009; Thorn et al., 2010). By recording from multiple neurons in the dopamine-depleted state during the course of learning, we here sought to determine whether the effects of dopamine depletion were selective for different phases of the task performance or for different stages of learning. By subsequently recording during dopamine replacement therapy with L-DOPA, we asked whether depletion-induced changes in striatal firing could be reversed. Our findings suggest that the dynamics of striatal circuit function are targeted by dopamine depletion, yielding multiple specific transformations in the parkinsonian state only some of which are correctible by L-DOPA therapy.

\section{Materials and Methods}

Animals, dopamine depletion and tetrode implantation. All experimental procedures were approved by the Committee on Animal Care of the Massachusetts Institute of Technology and were in accordance with the National Research Council's Guide for the Care and Use of Laboratory Animals. Twenty-one adult male Sprague-Dawley rats (310-420 g) were housed in pairs in a cubicle with reverse light cycle (lights on: 9:00 P.M.9:00 A.M.), and all training and recording sessions were given during their active cycle (dark period). After surgical implantation of the headstage for chronic neural recording, the rats were housed in individual cages and placed on food restriction ( $90 \%$ of their initial body weight) before training. Overview of the experimental time line is shown in Figure $1 C$.

To deplete dopaminergic terminals locally in the striatum, rats were anesthetized with a mixture of ketamine $(100 \mathrm{mg} / \mathrm{kg})$ and xylazine $(10$ $\mathrm{mg} / \mathrm{kg}$ ), and 6-hydroxydopamine (6-OHDA; $10 \mu \mathrm{g}$ per $3 \mu \mathrm{l}$ per site) was injected at a flow rate of $1 \mu \mathrm{l} / \mathrm{min}$ in the right hemisphere targeting the dorsolateral striatum at the following two locations: anteroposterior $(\mathrm{AP})=1 \mathrm{~mm}$, mediolateral $(\mathrm{ML})=-3 \mathrm{~mm}$, dorsoventral $(\mathrm{DV})=-4.5$ $\mathrm{mm}$; and $\mathrm{AP}=0.2 \mathrm{~mm}, \mathrm{ML}=-3.6 \mathrm{~mm}, \mathrm{DV}=-5 \mathrm{~mm}$.

Four weeks after the 6-OHDA lesion, each rat was anesthetized again with ketamine and xylazine for implantation of a headstage (Neuralynx) loaded with 12 tetrodes, 6 targeting the intact left dorsolateral striatum and 6 targeting the right dorsolateral striatum previously injected with 6-OHDA ( $\mathrm{AP}=0.5 \mathrm{~mm}, \mathrm{ML}= \pm 3.6 \mathrm{~mm}$ ). Tetrodes were made by twisting and heat fusing four insulated $12 \mu \mathrm{m}$ nickel-chromium $(\mathrm{Ni} / \mathrm{Cr})$ wires and then by coating them with cyanoacrylate glue (Pacer Technology) for $5 \mathrm{~s}$. The diameter of the tetrodes was $\sim 50 \mu \mathrm{m}$. Tetrodes were loaded into microdrives of the implantable headstage that allowed independent mobility of each tetrode (Jog et al., 2002). The headstage was secured to the skull with dental cement and jeweler's screws. During the week following surgery, tetrodes were lowered gradually to their target depths (3.5-4 mm). Tetrodes were not moved during training, except for small movements $(<100 \mu \mathrm{m})$ necessary to maintain high-quality recordings. The device was grounded through a screw anchor to the skull of the rat.

Behavioral training and data collection. All behavioral training was done in a recording chamber equipped with a T-maze (Fig. $1 \mathrm{~A}$ ) and was controlled by a Med-PC behavioral system (Med Associates). The T-maze consisted of two raised polycarbonate runways (height $=22.9$ $\mathrm{cm}$ ), joined in the shape of a T. Dimensions of the long and short arms were $7.6 \times 121.9$ and $7.6 \times 73.7 \mathrm{~cm}$, respectively. Wooden walls painted black (height $=40.6 \mathrm{~cm}$ ) surrounded the maze at a distance of 11.4-20.3 $\mathrm{cm}$. A drawbridge gate, which was raised and lowered manually, separated the starting block at the end of the long arm from the rest of the maze. Photobeam units were embedded into the walls along the maze to monitor the position of a rat and to provide input to the software that controlled behavioral training. An additional photobeam detected the opening of the start gate. Movements of the rat were additionally monitored with a video tracker (Neuralynx), which identified the location of an LED attached to the implanted headstage in video images captured at $30 \mathrm{~Hz}$ by an overhead CCD camera.

One week before surgery to implant the headstage, each rat was acclimated to the T-maze in five daily sessions. The rat was placed in the maze for $30 \mathrm{~min}$. Chocolate sprinkles were placed throughout the maze, and rats were allowed to explore and eat ad libitum. In the last two or three sessions, only the two goal sites were baited, and rats could obtain the reward by reaching the goals. In one to two final acclimation sessions, rats received up to 10 trials in which they had to wait at the start location while both goal arms were baited; they could run in the maze only after the gate was opened. Tones ( $1 \mathrm{kHz}$ or $8 \mathrm{kHz}$ ) were played at the middle of the run so the rats became familiar with the stimuli, but the tones did not indicate baited location.

Training on the T-maze task (Fig. $1 A, C$ ) began 1 week after implantation of the headstage. Rats were required to sit in the starting block until a warning click was presented and the gate was opened immediately. They were then free to run on the maze toward the goal arms. When they broke a photobeam approximately halfway down the long arm, an auditory cue ( $1 \mathrm{kHz}$ or $8 \mathrm{kHz}$ pure tone) was presented to signal the direction they should turn to receive a reward. The auditory cues remained on until the rat reached the end of a goal arm. The rats received chocolate sprinkles when they reached the correct baited goal and were guided back to the start position after they consumed the reward. During each trial, task events detected by photobeam breakage (gate opening, locomotion onset, turn onset/offset, and goal-reaching) or controlled by the computer (warning click and instruction cue onset) were time-stamped and saved for later analysis. The rat received a single session consisting up to 40 trials each day, and acquisition training continued until the rat made the correct response (reaching the baited goal) in at least $72.5 \%$ of the trials $\left(p<0.01 ; \chi^{2}\right.$ test $)$. These animals then received an additional 10 sessions of overtraining.

Once the overtraining was completed, 14 rats received up to 10 additional daily sessions, each preceded by an intraperitoneal injection of a mixture of L-DOPA $(6 \mathrm{mg} / \mathrm{kg})$ and benserazide $(15 \mathrm{mg} / \mathrm{kg})$ given $30 \mathrm{~min}$ before the start of the session. These low doses were chosen to prevent the development of dyskinesias. Before and/or after the set of these L-DOPA sessions, a subset of rats was given one or two training sessions with saline injection ( $1 \mathrm{ml} / \mathrm{kg}$, i.p.) given $30 \mathrm{~min}$ before the sessions.

Neuronal recordings. Throughout the training, spike activity was recorded (gain: $1000-10,000$, filter: $600-6000 \mathrm{~Hz}$, sampling rate: $30 \mathrm{kHz}$ or $32 \mathrm{kHz}$ ) using a Cheetah Data Acquisition System (Neuralynx), for $\sim 1$ $\mathrm{ms}$ ( 1.056 or $0.998 \mathrm{~ms}$, respectively) around the time when the signal crossed a preset voltage threshold on any one of the four tetrode channels. A tetrode channel lacking spike activity served as a reference channel. For each trial, data collection began with a $2 \mathrm{~s}$ baseline period preceding the warning click, and ended $1 \mathrm{~s}$ after goal-reaching detected by a photobeam placed over the food well containing reward or at trial end determined by the experimenter (rat's stopping in the maze over $30 \mathrm{~s}$, falling from the elevated T-maze, etc.). These neural data were timestamped synchronously with stimulus and behavioral events marked by the breakage of photobeams located along the maze or by TTL pulses from a PC controlling task training. Since data collection was terminated $1 \mathrm{~s}$ following goal-reaching, we could not analyze neuronal activity during the extended post-reward period or the full intertrial interval.

Local field potential (LFP) activity was also recorded concurrently with spike data and was analyzed for the effects of dopamine depletion and L-DOPA treatment. These results, demonstrating changes in oscillatory activity and spike-LFP coupling, have been published previously (Lemaire et al., 2012).

Fast-scan cyclic voltammetry. Headstages like those described above were loaded with eight carbon fiber probes (Clark et al., 2010) attached to independently movable microdrives for voltammetric measurements in the dorsolateral striatum and two tungsten bipolar electrodes $(75 \mu \mathrm{m}$ diameter; FHC) for stimulation of the medial forebrain bundle (MFB). Sprague-Dawley rats $(n=4)$ with unilateral 6-OHDA lesions of the dorsolateral striatum were anesthetized with ketamine/xylazine mixture and implanted with the headstages as above. Probes were lowered slowly to their target sites in the dorsolateral striatum $(\mathrm{AP}=+0.5 \mathrm{~mm}, \mathrm{ML}=$ $\pm 3.6 \mathrm{~mm}, \mathrm{DV}=3.5-4.0 \mathrm{~mm}$ ), and an $\mathrm{Ag} / \mathrm{AgCl}$ reference electrode (500 
Table 1. Classification of units recorded

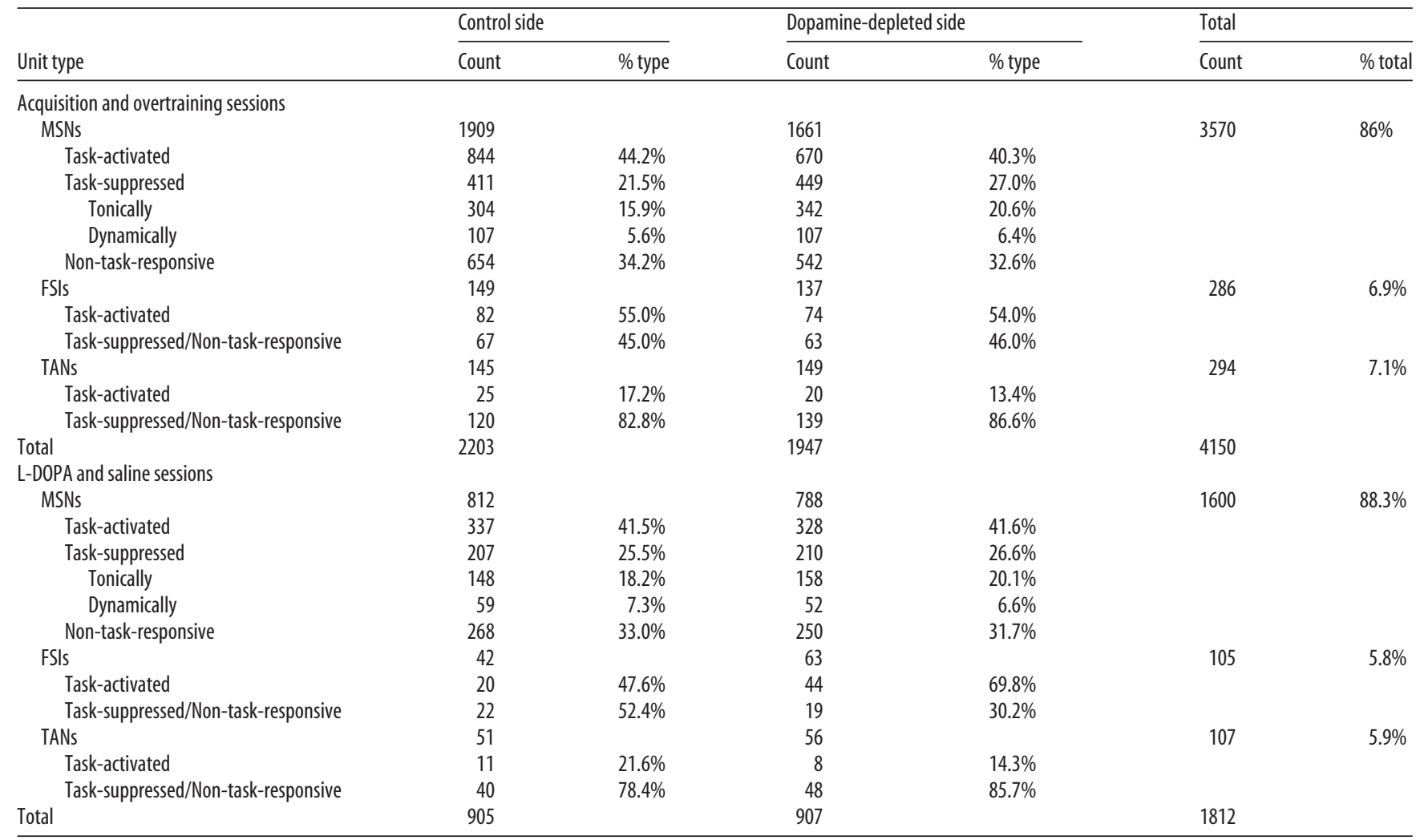

$\mu \mathrm{m}$ diameter; AM Systems) was implanted $0.5 \mathrm{~mm}$ into posterior cortex $(\mathrm{AP}=-0.3 \mathrm{~mm}, \mathrm{ML}=2.1 \mathrm{~mm})$. A triangular voltage waveform $(-0.4$ $\mathrm{V}$ to $1.3 \mathrm{~V}$ relative to the $\mathrm{Ag} / \mathrm{AgCl}$ reference) was applied every $100 \mathrm{~ms}$ to the carbon fiber probes until stable, background subtracted current measurements at the dopamine oxidation potential $(\sim 0.6 \mathrm{~V})$ could be obtained from every electrode (see Fig. 2). Data collection, waveform, and stimulation parameters were controlled via software written in LabView and two PCI data acquisition cards (National Instruments). Biphasic electrical stimulation $(60 \mathrm{~Hz}, 2$ ms pulse width, $200 \mu \mathrm{A})$ was applied to the electrodes in the MFB ( $\mathrm{AP}=-4.9 \mathrm{~mm}, \mathrm{ML}= \pm 1.3 \mathrm{~mm}, \mathrm{DV}=$ $6.5-7.5 \mathrm{~mm}$ ) while currents generated by dopamine oxidation at the surface of the carbon fiber electrode were measured in either the dopamine-depleted or control striatum. Currents measured at the dopamine oxidation potential were converted to concentration measures from poststimulation electrode calibrations obtained in vitro. After measuring dopamine release from both the control and lesion sides, L-DOPA $(6 \mathrm{mg} / \mathrm{kg}+$ benserazide $15 \mathrm{mg} / \mathrm{kg}$ ) was delivered intraperitoneally and stimulations were repeated. All probes were first tested for reliable detection of stimulated dopamine release in nondepleted zones, and those failing this test were discarded from analysis. Data from the remaining probes were averaged for those in the control $(n=7)$ and dopaminedepleted $(n=12)$ dorsolateral striatum and for those in the nondepleted zone on the side with 6-OHDA lesions $(n=2)$.

Behavioral data analysis. Behavioral performance was measured by response accuracy, reaction time (time from gate opening to locomotion start), and run time (time from locomotion start to goal-reaching). Training-related changes in these measures were analyzed using ANOVAs. Video tracker data and video images were reviewed to detect any changes in behavioral patterns over the course of training.

To combine the behavioral and neuronal data across groups of rats that learned the task at different rates, learning stages were defined based on the performance of the rat measured in percentage of correct trials. Stages 1 and 2 were days 1 and 2 of training, respectively. Stage 3 was defined as the day the rats performed correctly on at least $60 \%$ of the trials for the first time, and stage 4 was the first session in which they reached $>70 \%$ correct. Although rare, a single session could be included in more than one stage. For example, if the percentage correct on day 2 exceeded $60 \%$, that session would be assigned to both stages 2 and 3 . Stages $5-10$ were the pairs of successive sessions in which performance was $>72.5 \%$. Overtraining sessions with performance below this criterion were not included in the analysis with these behaviorally defined learning stages.

Neuronal data were also analyzed by dividing all training sessions into three phases: acquisition (day 1 to the first session with acquisition criterion of $\geq 72.5 \%$ performance), early overtraining (first to fifth overtraining sessions), and late overtraining (sixth to last overtraining sessions). For this staging method, all sessions were included regardless of performance during individual sessions.

Neuronal data analysis. Recorded spikes were manually sorted into different clusters (units) using Offline Sorter (Plexon). Units were graded for quality on the bases of cluster separation and the presence of absolute refractory periods, and accepted units were classified as putative MSNs, FSIs, or TANs based on their firing rate, spike waveforms, interspike intervals, and peri-event raster plots (see Fig. 3) (Barnes et al., 2005; Kubota et al., 2009; Thorn et al., 2010; Barnes et al., 2011).

For each unit, peri-event time histograms were created for each timestamped task event (warning click, gate opening, start, tone onset, turn onset and offset, and goal-reaching). An MSN unit was judged as task activated if its firing rate exceeded 2 SDs above its average firing rate during a pre-trial $500 \mathrm{~ms}$ baseline period (1900-1400 ms before warning click) for three consecutive $20 \mathrm{~ms}$ bins in any $\pm 200 \mathrm{~ms}$ peri-event window. Suppression of firing during task time was defined by applying a threshold level of 1 SD below the baseline mean firing rate; baseline activity was often too low to use a mean -2 SD criterion for activity suppression. With this criterion, MSNs suppressed throughout task time following task start (breakage of a photobeam placed immediately outside the start gate) were classified as tonically suppressed MSNs, and those with suppression in at least one, but not all, post-start task periods were considered as dynamically suppressed MSNs. Units that did not meet either activation or suppression criterion were not included in further analyses because of a lack of detectable task-related modulation ("non-task-responsive" units in Table 1). 
A

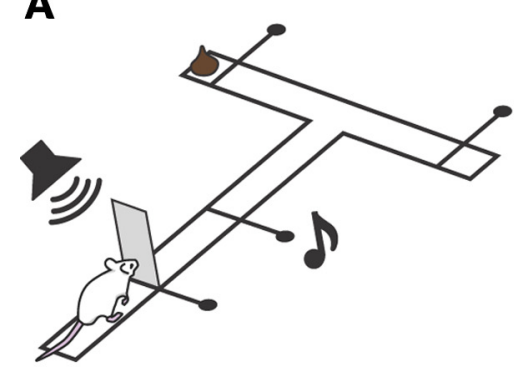

B

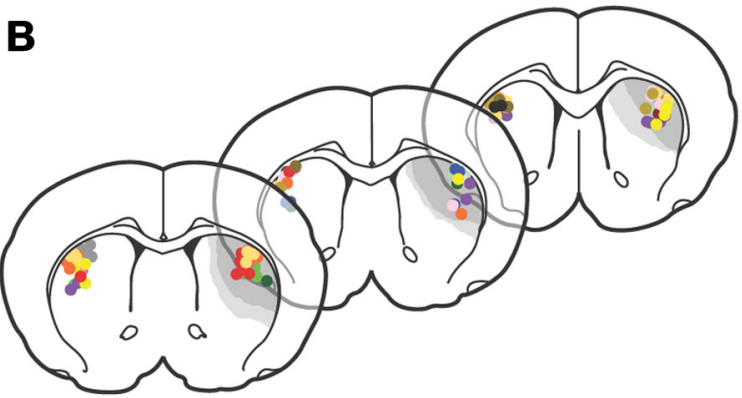

C
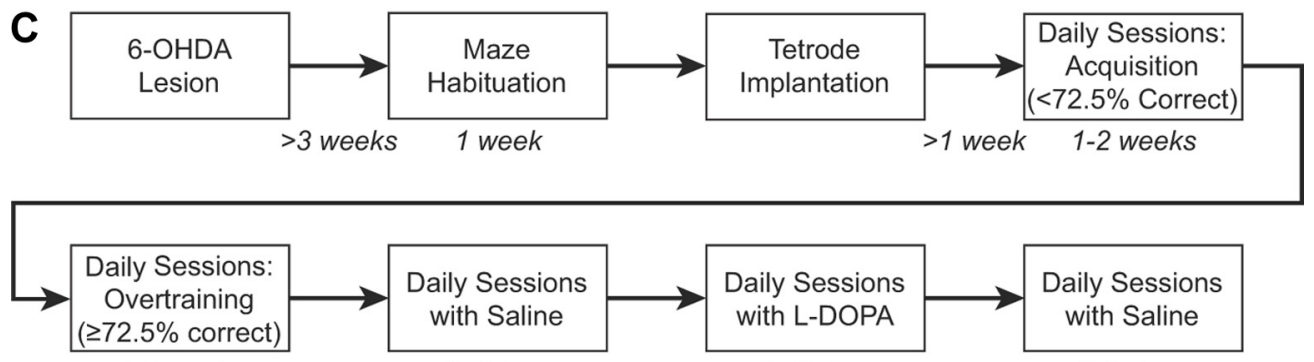

1-2 weeks
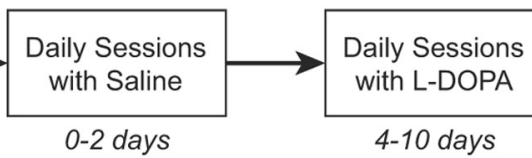

Daily Sessions with Saline

D
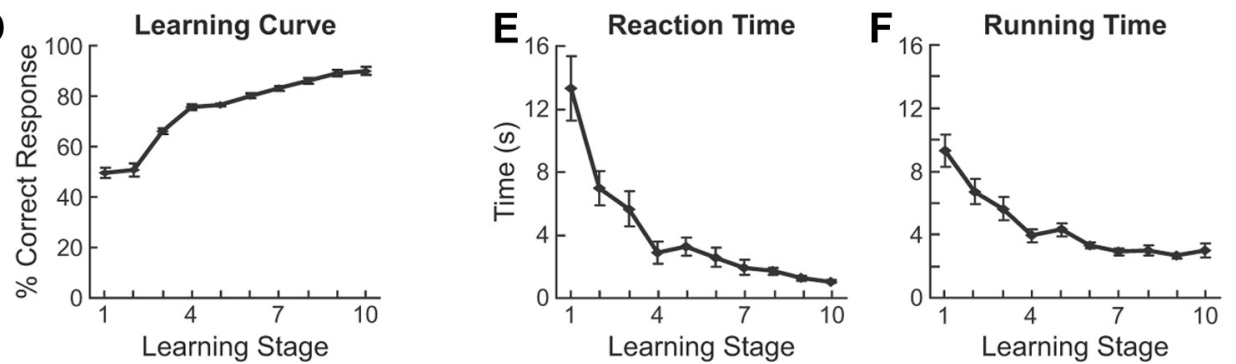

Figure 1. Experimental design and behavioral results. $\boldsymbol{A}$, The T-maze task. $\boldsymbol{B}$, Recording sites in the dopamine-depleted region (light gray) and in contralateral intact region in the dorsolateral striatum. Colors indicate different rats. $\boldsymbol{C}$, Experimental timeline. $\boldsymbol{D}-\boldsymbol{F}$, Percentage of correct response $(\boldsymbol{D})$, response reaction time (gate opening to start, $\boldsymbol{E}$ ), and running times (start to goal reaching, F) averaged across all rats. Training stages are as follows: $1=$ first day of training; $2=$ second day of training; 3 and $4=$ first session with percent-correct $\geq 60$ and $70 \%$, respectively; $5-10=$ 2 consecutive sessions with performance above a learning criterion (percent-correct $\geq 72.5 \%$ ) combined for each stage. Error bars indicate SEM.

For the units classified as FSIs and TANs, task-activated subpopulations were determined with criteria identical to those for MSNs: activity exceeding 2 SDs above its pre-task baseline firing rate for three consecutive $20 \mathrm{~ms}$ bins in any $\pm 200 \mathrm{~ms}$ peri-event window. Very few FSIs and TANs met the criteria for task-suppressed categories, and they were not analyzed as separate populations.

For each unit, the mean number of spikes across all trials in a session was determined for each $10 \mathrm{~ms}$ bin in a $500 \mathrm{~ms}$ pre-trial baseline period and successive $\pm 200 \mathrm{~ms}$ peri-event windows. Activity of each unit was then converted with each of the following four methods, yielding four different activity measures. (1) Average raw spike counts were smoothed with a 5-point averaging filter. (2) Spike count for each bin was normalized to a scale of 0 (minimum count) to 1 (maximum count). (3) Spike count for each bin was normalized by calculating $z$-scores based on the mean (Smean) and SD (Sstd) across all bins in the baseline and peri-event periods $($ Zbin $=($ Sbin - Smean $) / S$ std $)$. (4) $Z$-score for each bin was normalized to the pre-trial baseline activity by subtracting the mean $Z$-score for the baseline period. To obtain population activity for each neuronal population (e.g., task-activated MSNs) across training stages, data converted with each of these four methods were averaged across all units in the neuronal category recorded during the session belonging to each training stage. Changes across training stages and task time, and differences between the control and dopamine-depleted sides, were tested by averaging activity of each unit for $200 \mathrm{~ms}$ periods before and after each event and by performing ANOVAs on these averaged data.

Histology. Following the completion of experiments, rats were anesthetized with sodium pentobarbital solution $(\sim 40-50 \mathrm{mg} / \mathrm{kg})$, and current was passed through each tetrode to make lesions that marked the ends of the tetrode tracks ( $25 \mu \mathrm{A}, 10 \mathrm{~s})$. Two days later, rats were deeply anesthetized with a lethal dose of sodium pentobarbital ( $\sim 100-145 \mathrm{mg} /$ $\mathrm{kg}$ ), and brains were fixed by transcardial perfusion with $4 \%$ paraformaldehyde in $0.1 \mathrm{M} \mathrm{KNaPO}_{4}$ buffer. Brains were postfixed and cut into coronal slices at $30 \mu \mathrm{m}$ on a sliding microtome. Sections were processed for Nissl and tyrosine hydroxylase, and were examined microscopically to identify the dopamine-depleted region and the tetrode tracks. The extent and location of lesions varied from rat to rat, but dopamine depletion was uniformly located in the dorsolateral striatum. Tetrodes with tracks that ended out of the depleted zone or the dorsolateral striatum were disregarded for this study (Fig. 1B).

\section{Results}

Twenty-one rats were trained on the conditional T-maze task illustrated in Figure $1 A$, following recovery from injections of 6-OHDA made in the dorsolateral striatum of the right hemisphere (Fig. $1 B$ ) and subsequent implantation of tetrodes (Fig. $1 B, C)$. The rats were notified of the initiation of each trial with a click followed by the opening of a start gate, and were cued in the middle of the maze run by one of two auditory cues indicating the correct direction to turn for the chocolate reward (Fig. 1A). The localized unilateral dopamine depletion was located in the sensorimotor striatum (Fig. 1B). Despite evidence that excitotoxic lesions made in the dorsolateral striatum following the acquisition of the T-maze task impair performance of the learned behavior (W. E. Decoteau, D. Hu, 
A
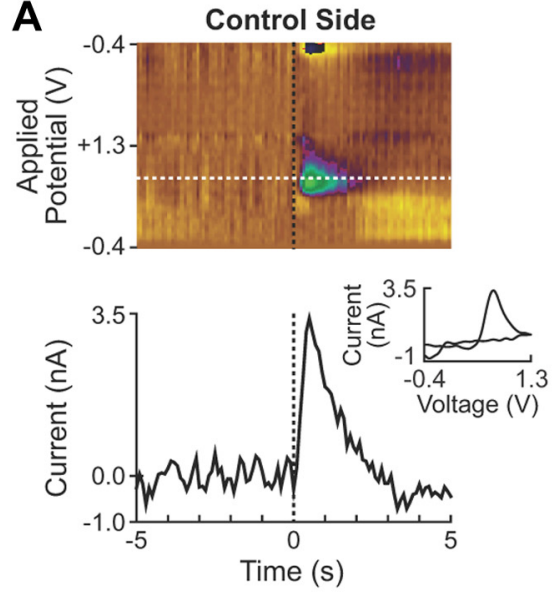

Dopamine-Depleted Side
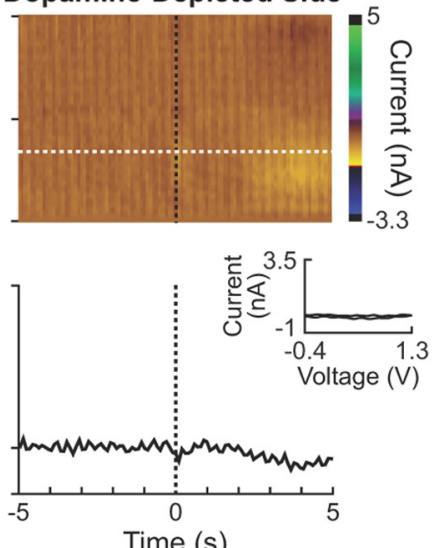

B

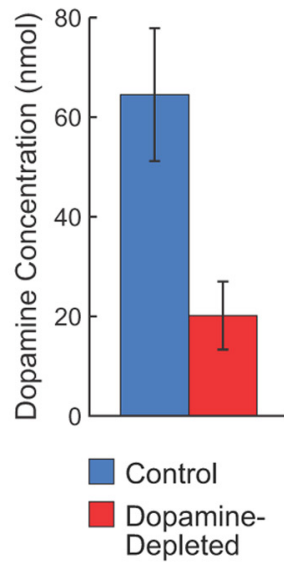

C Dopamine-Depleted Zone

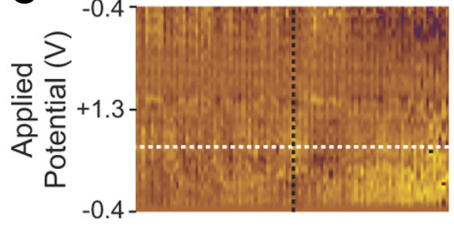

Non-Depleted Zone
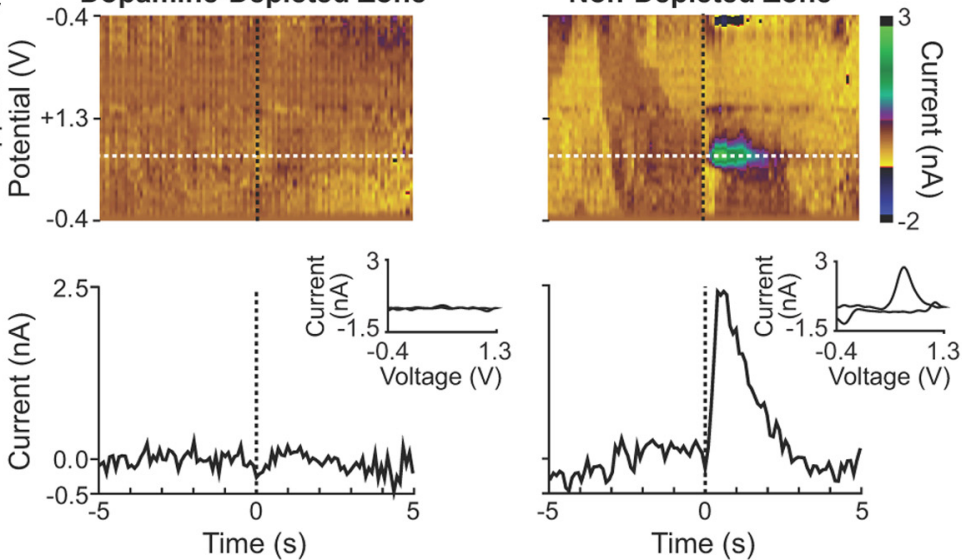

Figure 2. Dopamine depletion measured with fast-scan cyclic voltammetry. A, Examples of dopamine release measured in the dorsolateral striatum on the control (left) and 6-0HDA lesion (right) sides. Top, Redox currents as a function of potential during consecutive voltammetric scans around the time of MFB electrical stimulation (time 0 ). Note the increase in current around the peak dopamine oxidation potential ( $0.6 \mathrm{~V}$; white dashed line). Bottom, Currents generated by dopamine oxidation showing release on the control side (left) and its absence on the 6-0HDA lesion side

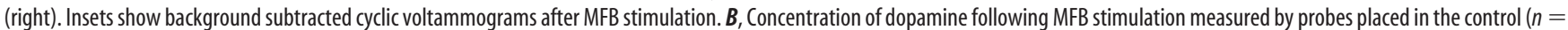
7) and dopamine-depleted ( $n=12$ ) striatum of four rats. C, Phasic dopamine release at a representative site in the dopamine-depleted region in the dorsolateral striatum (left) and a site ventral to the depleted zone in the same hemisphere (right) in response to MFB stimulation, shown as in $\boldsymbol{A}$.

Y. Kubota, and A. M. Graybiel, unpublished observation) and that intact dopamine input to this region is necessary for habit formation of instrumental behaviors (Faure et al., 2005), this highly spatially restricted dopamine depletion did not produce detectable deficits in learning and performance of the task. All 21 rats reached the acquisition criterion (correct responses in at least $72.5 \%$ of trials per session, designated as training stage 5) in an average of 8.3 sessions, a rate comparable to that of normal, nondepleted rats studied previously (Barnes et al., 2005). Their average percent-correct performance rose from chance levels during learning stages $1-2$ to $>85 \%$ late in overtraining (stages $8-10 ; p<0.0001$, ANOVA, Fig. $1 D$ ). Their reaction times (from gate opening to start) and running times (from start to goal-reaching) tended to be longer than those we have observed for normal rats early in training (stages 1-3), but thereafter were comparable (Barnes et al., $2005)$. Both reaction and running times decreased significantly as the rats acquired the T-maze task (Fig. $1 E, F ; p<$ 0.0001 for both).

During this entire training period (3-6 weeks), we recorded single-unit activity in the striatum with six tetrodes per hemisphere, in daily sessions. The total dataset included 5962 units, with 2854 recorded in the dopamine-depleted striatum, and 3108 in the striatum of the control side (Table 1). Units were classified into sets of putative MSNs (5170, 86.7\%), FSIs (391, 6.6\%), and TANs (401, 6.7\%). The proportions of each putative neuronal subtype were comparable for recordings made in the control and dopamine-depleted striatal regions ( $p>0.08, \chi^{2}$ test; Table 1$)$.

We kept the depth of each tetrode as constant as possible across recording sessions, making only small advances to maintain activity with discrete spikes. It is thus likely that many of these units were single neurons recorded repeatedly in multiple sessions. For the purposes of the analyses described here, and for tracking neuronal activity across learning, all of the recorded units were included in the aggregate firing rates; however, by calculating correlations of spike waveforms of units recorded on consecutive sessions (Emondi et al., 2004; Kubota et al., 2009), we estimated that there were 3291 unique units among the 5794 recorded units.

In four additional rats, we used fast-scan cyclic voltammetry to measure dopamine release evoked within the targeted zone of depletion and its contralateral counterpart by stimulation of the MFB. The 6-OHDA injections were effective in depleting dopamine to levels less than a third of those on the noninjected side (Fig. 2A,B). By contrast, stimulated dopamine release was spared at sites $1 \mathrm{~mm}$ ventral to the injection site, confirming that the 
lesions were spatially restricted to the dorsolateral striatum (Fig. $2 C)$. Together, these findings suggest that the intrastriatal dopamine depletion was severe, but was localized.

\section{Neuronal subtypes recorded in the control and dopamine-depleted striatum}

The MSNs that we recorded could be divided broadly into taskactivated and task-suppressed populations (Table 1) by comparing their firing rates during task time (from warning click to goal-reaching) with their firing rates during the pre-task baseline period (Barnes et al., 2005; Kubota et al., 2009; Thorn et al., 2010; Barnes et al., 2011). Dopamine depletion did not affect the percentage of neurons classified as being within these populations (Fig. 3A). On the control side, $44.2 \%$ of MSNs had excitatory phasic responses to some task event and therefore were called task activated (an example is shown in Fig. 3B); the corresponding number for the dopamine-depleted side was $40.3 \%$. Activity of approximately one-quarter of the recorded MSNs (21.5 and $27.0 \%$, respectively) was suppressed during the maze runs, and they were thus called task suppressed. The remaining MSNs (non-task-responsive, 32-34\% on both sides) did not meet the criterion for either task activation or task suppression. Among the task-suppressed MSNs, there were two subgroups that emerged from the analysis: units whose firing rates were tonically suppressed and units whose firing rates were dynamically suppressed. The spike activity of the tonically suppressed MSNs fell when the rats commenced the maze runs, and their activity remained low throughout the run time (Fig. 3C); the dynamically suppressed MSNs gradually regained their pre-run firing rates during some, but not all, peri-event intervals after a drop at run start. Among putative striatal interneurons, we also identified task-activated and task-suppressed FSIs and TANs (examples are shown in Fig. $3 D, E$ ), but the task-suppressed FSI, task-activated TAN, and task-suppressed TAN populations were small. We therefore performed analysis on the ensemble activity of taskactivated FSIs and all recorded TANs.

\section{Differential effects of dopamine depletion on firing patterns of striatal MSNs in the sensorimotor striatum}

The task-activated MSNs recorded in the dopamine-depleted striatum fired at markedly higher rates than those in the contralateral control striatum $\left(p=2.21 \times 10^{-15}\right.$ for the pre-run baseline period and $p=3.65 \times 10^{-19}$ for the maze-run period, ANOVA; Fig. $4 A, B, E$ ). These differences in firing rate were initially pronounced mainly during the maze runs, but by the end of training generalized to the entire pre-task and in-task periods. Responses to individual task events also became more sharply defined in the dopamine-depleted striatum than in the control striatum.

The tonically suppressed MSNs also had higher firing rates on the dopamine-depleted side $(p<0.0001)$. These increases occurred selectively during the pre-task baseline period, the period when these neurons were normally most active, and during the early task period before the onset of maze runs (warning click to gate opening). Their activity was equally suppressed on both sides during the maze runs, when these neurons were normally suppressed (Fig. 4C-E). Strikingly, this augmented pre-run firing did not appear during the initial acquisition training; it appeared only later, during the early overtraining period. The same training dependency also held for the activity of the dynamically suppressed MSN group: activity was also relatively similar on the two sides until early overtraining $(p>0.15)$, and then during the late overtraining period (training stages $8-10$ ), the firing rates of these MSNs on the dopamine-depleted side became elevated across the full pre-task and in-task periods ( $p<0.02$; Fig. $4 D, E)$.

These findings suggested a general pattern in which both the task-activated and task-suppressed MSNs in the region of dopamine depletion had elevated firing rates, but these changes were most pronounced during the periods in which the respective subtypes were active.

For the task-suppressed population, effects of dopamine depletion became significant with time. To determine whether these effects were due to progressive compensatory changes associated with the 6-OHDA lesions or whether they were dependent on training itself, we split the subjects into groups with short (8 rats, $31-38 \mathrm{~d}$, average $=35.8 \mathrm{~d}$ ) and long (7 rats, 39-64 d, average $=47.3 \mathrm{~d}$ ) delays between 6-OHDA lesions and the onset of T-maze training and examined activity of tonically suppressed MSNs separately in these two groups. This analysis showed that the enhanced firing during the pre-movement task time (i.e., after warning click and around gate-opening) developed with training in both groups (Fig. 5A), indicating that the effects of dopamine depletion on task-related activity was more likely to be learning dependent than related to the passage of postlesion time alone. By contrast, the activity during the pre-trial baseline period was enhanced during the acquisition phase only for the long delay group (Fig. $5 B$ ), suggesting that changes in the out-of-task activity might be dependent on the time elapsed after 6-OHDA administration. Thus, the contribution of learning to the dynamics of task-suppressed MSNs in the dopamine-depleted striatum could be selective for their activity during the period from task start (warning click) to run start.

Despite these changes in firing rate, dopamine depletion did not affect the learning-related plasticity of task-activated MSNs. During the course of training from the start of acquisition to overtraining, these neurons developed a pattern of activity that emphasized the beginning (warning cue to run start) and end (turning to goal-reaching) of the maze runs and de-emphasized the mid-run period (Fig. $4 A, B$ ). This task-bracketing activity pattern, which we reported previously for normal rats and mice (Jog et al., 1999; Barnes et al., 2005; Kubota et al., 2009; Thorn et al., 2010), formed in both dopamine-depleted and nondepleted hemispheres and could be identified clearly in the late overtraining phase.

\section{Learning-related changes in ensemble activity of striatal FSIs are severely disrupted by dopamine depletion}

The local dopamine depletion in the sensorimotor striatum almost fully blocked the development of the task-bracketing activity of the FSI populations during learning. This pattern did form on the control side (ANOVA comparing peri-event firing rates in the late overtraining phase, $p<0.02$ ), as we have reported previously for normal animals (Kubota et al., 2009). FSI ensemble activity recorded in the dopamine-depleted striatum was strong throughout the runs, with no hint of decreases in mid-run activity (Fig. $6 A, B, E$ ). Even in the late stages of overtraining (stages $8-10)$, during which there was slight reduction in firing rates around run start and before tone onset, differences in firing rates across peri-event windows did not reach significance $(p>0.4)$. Despite these marked changes in the in-task firing of the FSI ensemble, their baseline firing rates were unaffected (Fig. 6B, E). Similar results were found for rats with short and long delays between 6-OHDA lesions and training onset, indicating that the effects of dopamine depletion were unlikely to reflect timedependent compensatory changes alone (data not shown). These 
A

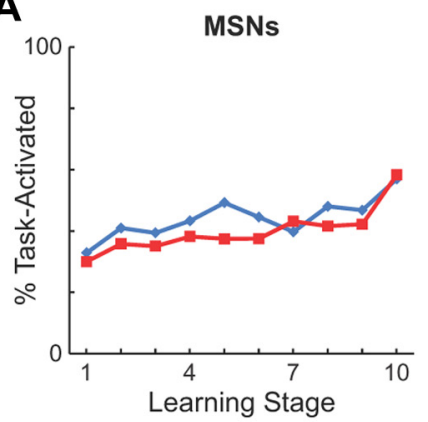

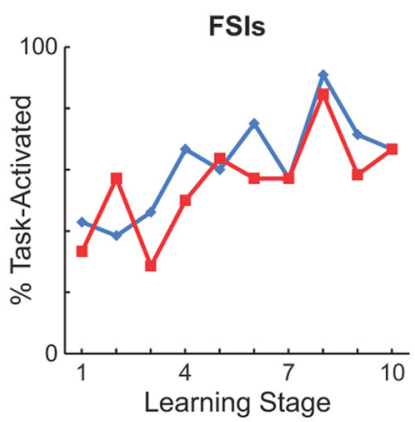

Inter-Spike Interval

B Task-activated MSN
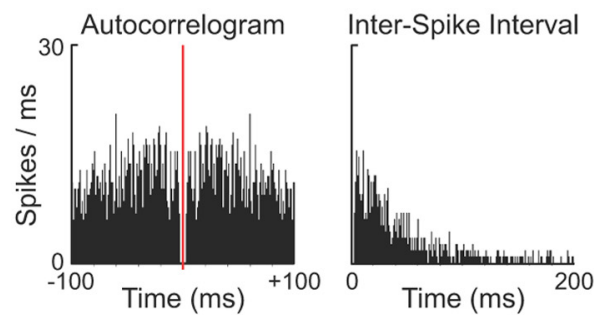

C Tonically-suppressed MSN

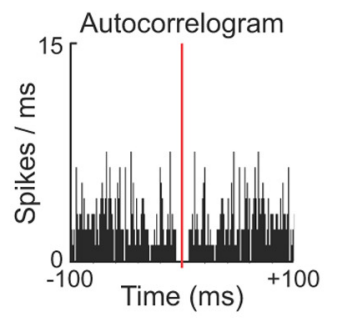

Inter-Spike Interval

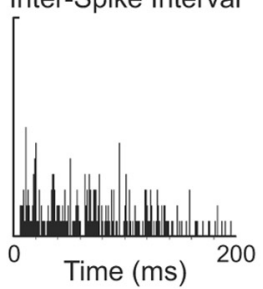

D Task-activated FSI
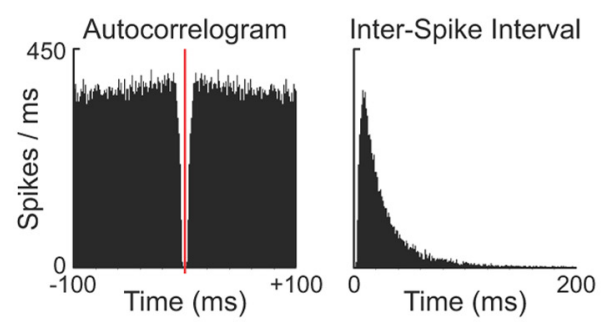

E Task-activated/suppressed TAN
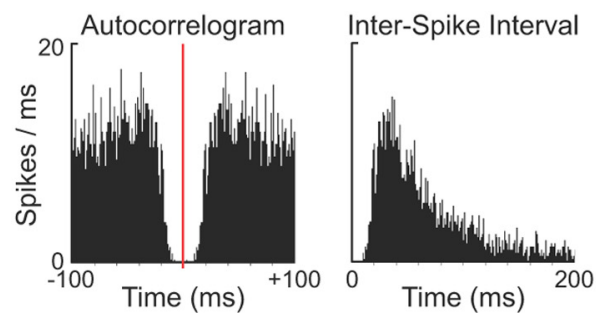
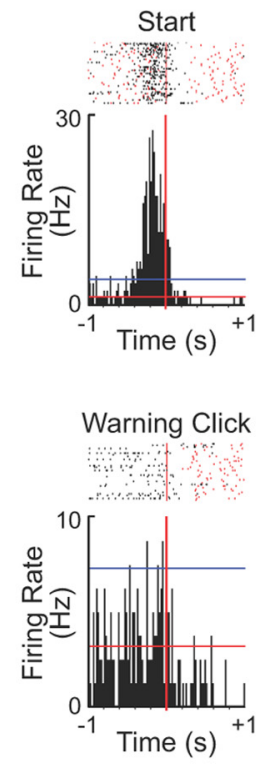

Left Turn On

Right Turn On
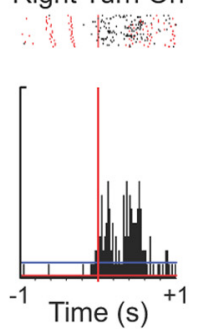

Right Goal


Right Turn On

Right Goal
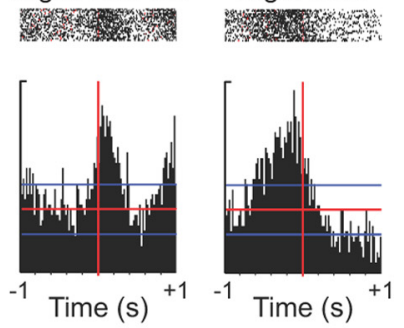

Warning Click

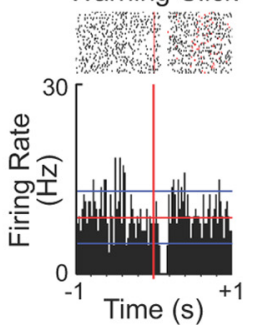

Right Goal
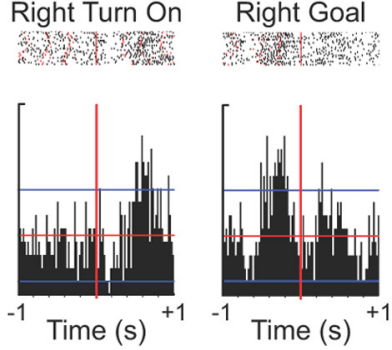

Figure 3. Classification of recorded units.A, Proportions of task-activated MSNs (left), FSls (middle), and TANs (right) during acquisition and overtraining, Learning stages are as in Figure 1D. B-E, Peri-event histograms and raster plots illustrating activity of putatively identified single units categorized as task-activated MSN (B), tonically suppressed MSN ( $\boldsymbol{C}$, task-activated FSI (D), and task-activated/suppressed TAN (E). For each unit, an autocorrelogram and interspike interval plotareshown at left. Peri-event histograms and raster plots for three task events atright illustrate task-related responses of these units. Red and blue horizontal lines in histograms represent the mean firing rates and \pm 2 SDs calculated for their pre-trial baseline activity, respectively. Red dots in raster plots indicate other task events.

findings demonstrate that the intrastriatal dopamine depletion largely blocked the learning-related emergence of a taskbracketing pattern typical of FSIs but did not alter pre-task FSI firing rates of the same FSI populations.
TANs formed the only neuronal population for which we found dopamine depletion to depress firing rates. This lowering of firing rates occurred during acquisition, and, unlike that for any of the other neuronal types we examined, the effects did not 

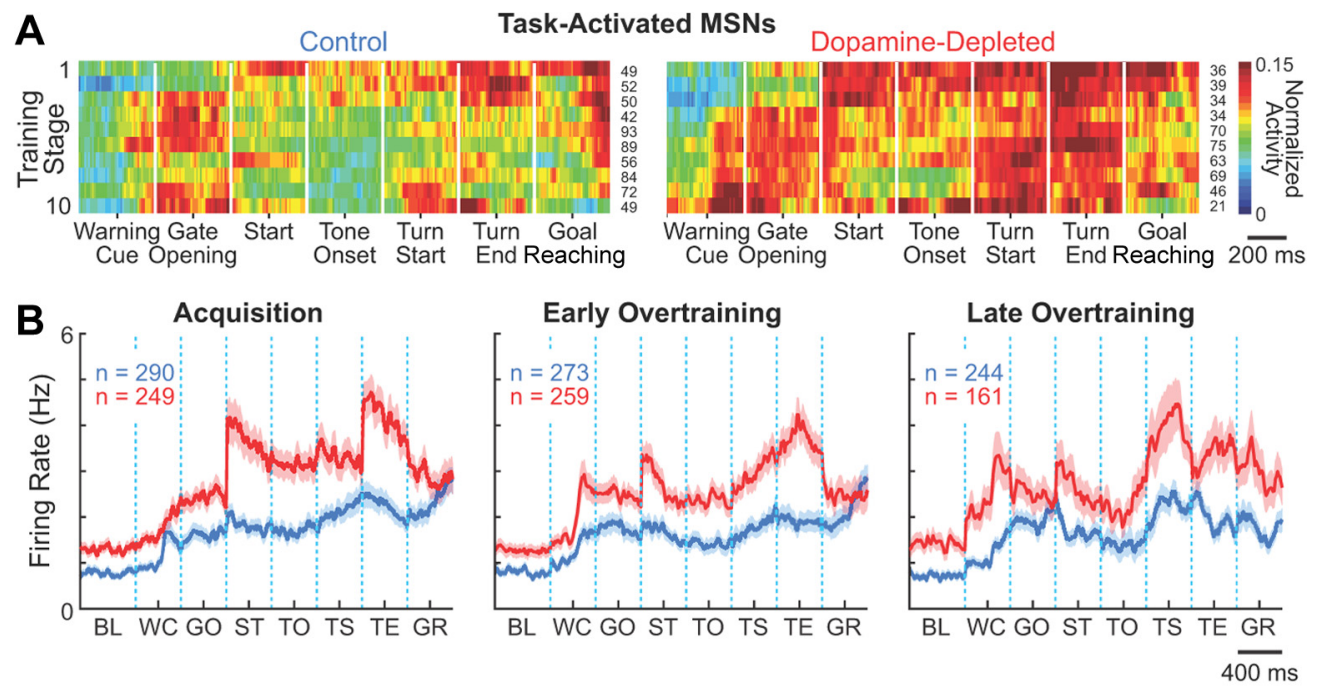

\section{C}
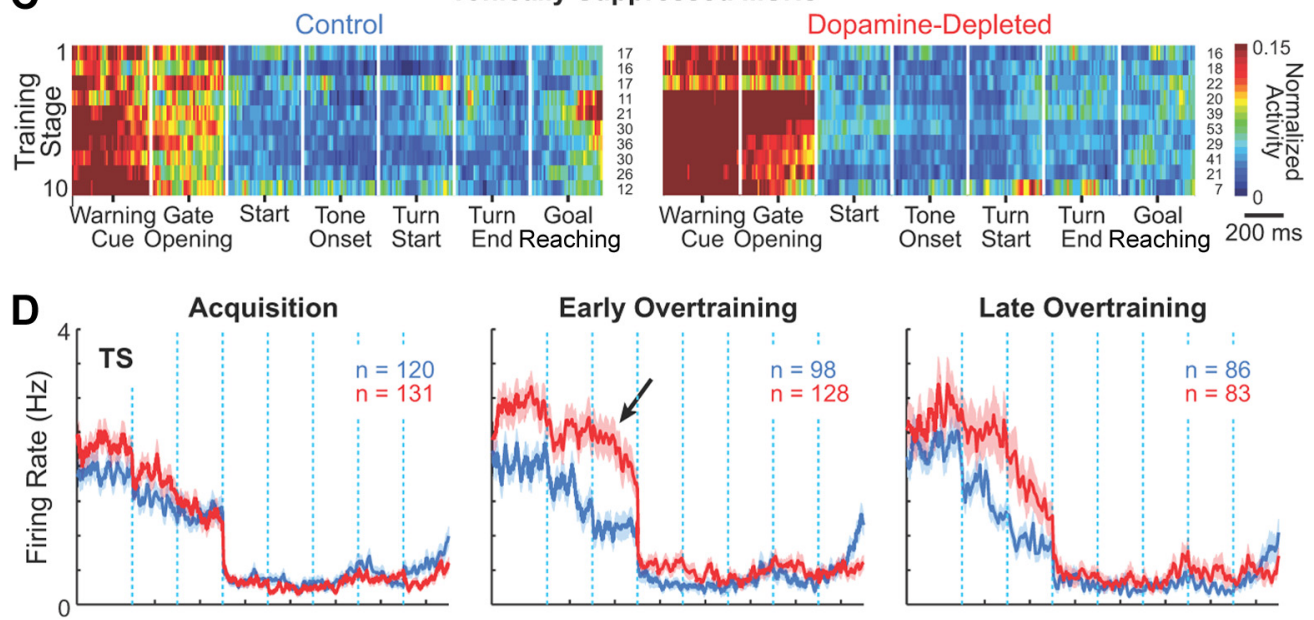

Early Overtraining
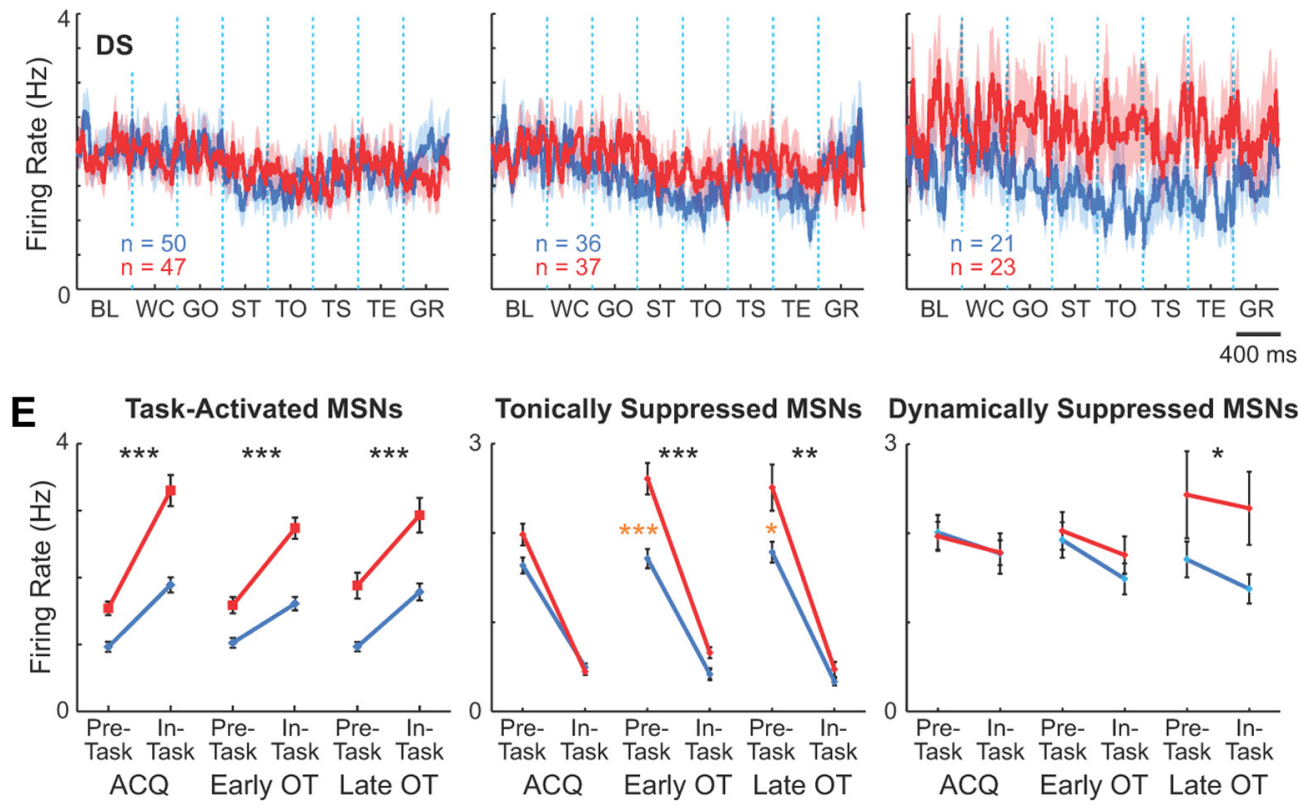

Tonically Suppressed MSNs

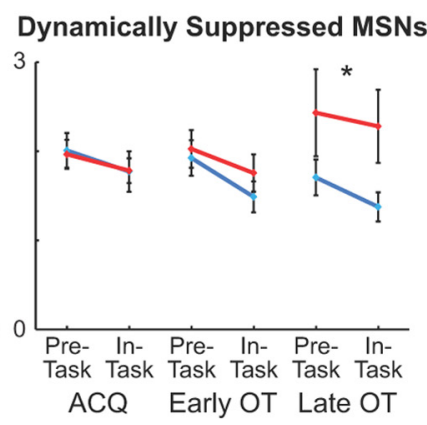

Figure 4. Selective disruption of activity of striatal projection neurons by dopamine depletion. $\boldsymbol{A}, \boldsymbol{C}$, Ensemble activity of putative task-activated $(\boldsymbol{A})$ and task-suppressed ( $\boldsymbol{C}$ ) MSNs recorded in the control (left) and dopamine-depleted (right) dorsolateral striatum. Firing rate of each unit during $\pm 200 \mathrm{~ms}$ around each of seven task events (as labeled on $x$-axis) were normalized to its minimum-to-maximum scale ( $0-1)$ and activity of individual units were averaged for each training stage (stages $1-10$ on $y$-axis). Color scale is shown at right. Numbers of units for the stage are indicated to the right of each row. $\boldsymbol{B}, \boldsymbol{D}$, Mean raw firing rates of task-activated (B) and task-suppressed (D) MSNs on the control (blue) and dopamine-depleted (red) sides during acquisition (stages 1-4), early overtraining (5-7), and late overtraining (8-10), plotted across task time. Shading represents SEM. Task-suppressed units were further classified to tonically suppressed (TS) and (Figure legend continues.) 
depend on task time (Fig. 6C-E). These effects were similar for the short and long delay subgroups, again suggesting that they were related not to time elapsed after dopamine depletion, but to T-maze learning (data not shown). We found only a small number of TANs that exhibited the characteristic pause in spiking at different task events (Fig. 3E). These units were found both on the control and dopaminedepleted sides in comparable proportions (23 and 26\%, respectively; $p>0.5, \chi^{2}$ test).

\section{L-DOPA treatment induces major changes in the firing patterns of striatal MSNs in the dopamine-depleted striatum}

After completion of the overtraining period, we pretreated 14 rats with daily injections of L-DOPA 30 min before they performed the T-maze task $(6 \mathrm{mg} / \mathrm{kg}+$ benserazide $15 \mathrm{mg} / \mathrm{kg}$, i.p., for 9-10 d). This procedure was designed to mimic the dopamine replacement therapy commonly given to patients with Parkinson's disease, and to test its effects on task performance and on neuronal activity in the dopamine-depleted sensorimotor striatum. The dose levels were kept low to avoid L-DOPA-induced abnormal movements. Before and/or after the series of L-DOPA sessions, a subset of the rats $(n=$ 9) also received 1-2 additional sessions with saline injections $(1 \mathrm{ml} / \mathrm{kg}$, i.p. $)$ as a control procedure.

In a separate set of rats $(n=3)$, we tested whether L-DOPA treatment increased striatal dopamine release induced by MFB stimulation. We found that it did both on the lesion side (294\% increase, $p=0.0094, t$ test) and on the control side $(510 \%$ increase, $p=0.054$ ), in accordance with previous observations (Keller et al., 1988).

The L-DOPA treatment did not affect the percent-correct performance of the animals (Fig. $7 A$, left). However, the rats appeared less motivated to run, potentially due to the rewarding effects of the drug, and their average reaction times increased from $1.5 \mathrm{~s}$ for the last three sessions of overtraining to $3.7 \mathrm{~s}$ for the first three L-DOPA sessions (Fig. 7A, middle; $p<0.05, t$ test). Reaction times slowly decreased as the L-DOPA administration was continued, but they remained higher than those before the start of treatment in 5 of the 14 animals. The total running times

\section{$\leftarrow$}

(Figure legend continued.) dynamically suppressed (DS) subpopulations. Arrow indicates increased pre-run firing rate in the dopamine-depleted side for TS units. Task events are as follows: baseline (BL; 1.9-1.4 s before warning click); warning click (WC), gate opening (G0), start (ST), tone onset (TO), turn start (TS), turn end (TE), and goal-reaching (GR). $\boldsymbol{E}$, Average pre-task (from 2 s before warning click to gate opening) and in-task (from start to goal reaching) firing rates of task-activated (left); tonically suppressed (middle); and dynamically suppressed (right) MSNs during acquisition, early overtraining, and late overtraining phases. Asterisks indicate significant differences in overall firing rates (black) and in period-specific firing rates (orange) between two sides $\left({ }^{*} p<0.05 ;{ }^{* *} p<0.01 ;{ }^{* * *} p<0.0001\right)$. Error bars indicate SEM. of the animals also tended to increase during L-DOPA sessions (from an average of $2.8 \mathrm{~s}$ for the last three overtraining sessions to $4.7 \mathrm{~s}$ for the first three L-DOPA sessions), but these changes did not reach statistical significance (Fig. $7 A$, right). Saline injection did not induce significant changes in behavioral performance (Fig. 7A) or in ensemble activity of different neuronal populations.

L-DOPA almost completely reversed the heightened pre-start firing rates of MSNs induced by dopamine depletion while preserving pre-start firing rates in the nondepleted striatum (Fig. $7 B-G)$. This normalizing effect of the L-DOPA therapy was evident for both the task-activated and the tonically task-suppressed MSN populations in the dopamine-depleted striatum (ANOVA comparing pre-task firing rates between the last five overtraining sessions vs the first five L-DOPA sessions, $p<0.005$ and $p<$ 0.001 , respectively). Pre-task activity was not affected by the daily L-DOPA treatment in the control striatum $(p>0.4$ and $p>0.6$ for task-activated and tonically task-suppressed MSNs, respectively). In addition, L-DOPA administration increased neuronal firing of task-activated MSNs in the dopamine-depleted striatum during maze runs $(p<0.05)$, principally around run start and before goal-reaching (Fig. $7 \mathrm{~B}, \mathrm{C}$ ). Again, firing rates in the nondepleted hemisphere were left nearly unchanged $(p>0.4)$. Thus, for the task-activated MSNs, L-DOPA treatment both decreased (pre-task) and increased (in-task) activity, whereas for the toni- 

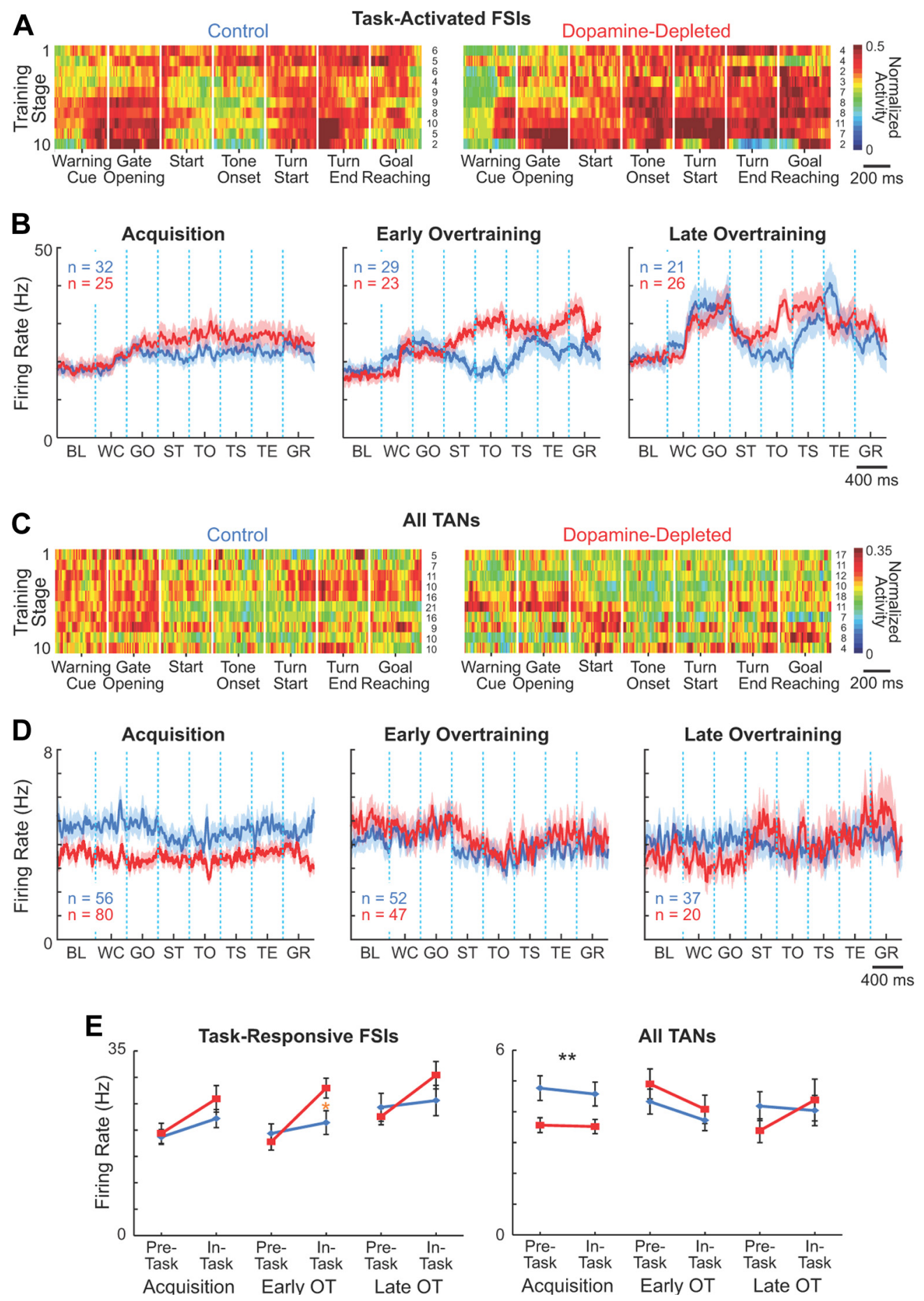

Figure 6. Effects of dopamine depletion on activity of striatal interneurons. $\boldsymbol{A}, \boldsymbol{C}$, Population activity of putative task-activated FSIs $(\boldsymbol{A})$ and all TANs $(\boldsymbol{C})$ recorded in the control (left) and dopamine-depleted (right) striatum, plotted as in Figure 4. For TANs, activity of the entire recorded population is shown because of small numbers of task-activated and task-suppressed units per training stage. $\boldsymbol{B}, \boldsymbol{D}$, Mean raw firing rates of task-activated FSIs (B) and all recorded TANs (D) on the control (blue) and dopamine-depleted side (red). $\boldsymbol{E}$, Pre- and in-task activity of task-activated FSIs (left) and all recorded TANs (right) during acquisition and overtraining. Asterisks indicate significant differences as in Figure 4E. BL, baseline; WC, warning click; G0, gate opening; ST, start; TO, tone onset; TS, turn start; TE, turn end; and GR, goal-reaching.

cally suppressed MSNs, L-DOPA administration only decreased activity (pre-task).

For the small number of FSIs that we were able to record in these late stages of chronic recording in the L-DOPA treatment sessions ( $n=10$ on the control side and 28 on the depleted side during first 5 L-DOPA sessions), we did not detect effect of L-DOPA treatment on their firing patterns (Fig. $8 A, B$ ). The only change we noted was a slight decrease in overall firing rate. This absence of marked effects of the dopamine replacement therapy stands in contrast to the severe disruption of learning-related plasticity of this group of interneurons produced by the original dopamine depletion, and suggests a possibility that abnormal FSI activity induced by dopamine depletion may not be rescued by restoring striatal dopamine levels. 
A

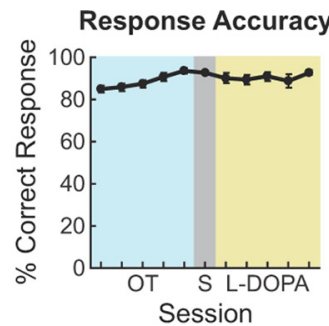

Reaction Time

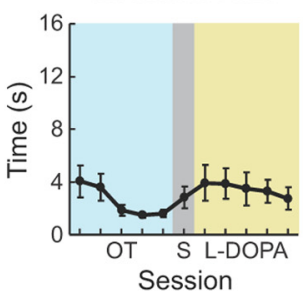

Running Time

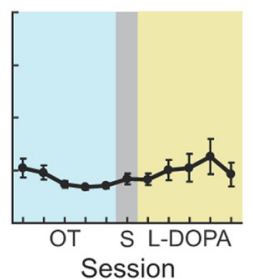

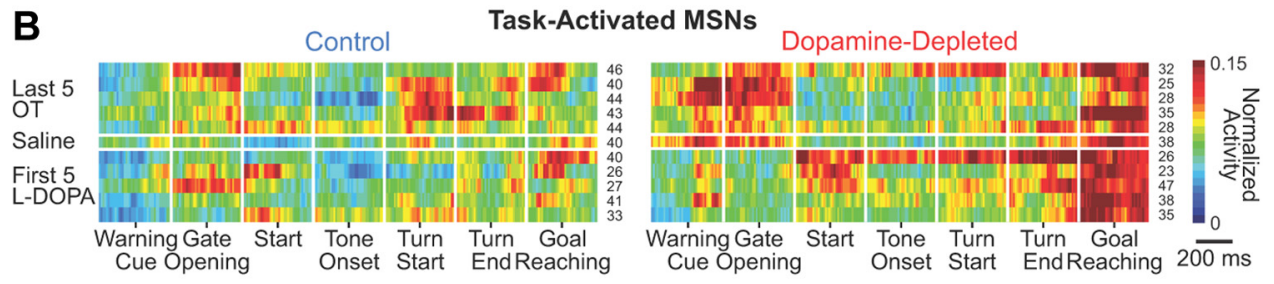

C

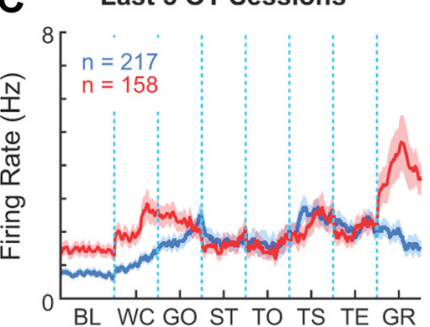

First 5 L-DOPA Sessions

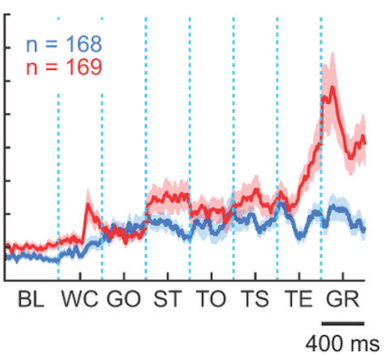

D

E

Tonically Suppressed MSNs
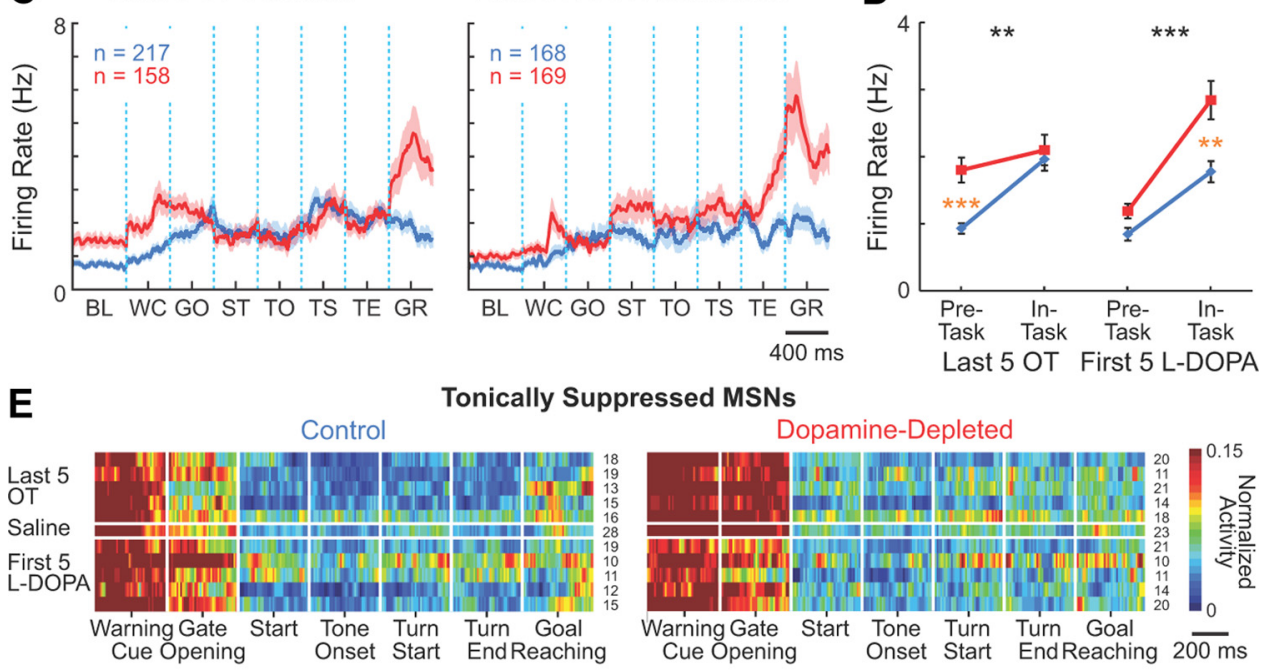

F

F Last 5 OT Sessions

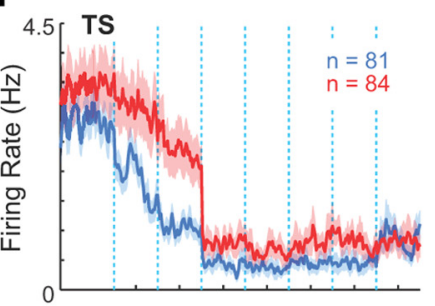

First 5 L-DOPA Sessions

G
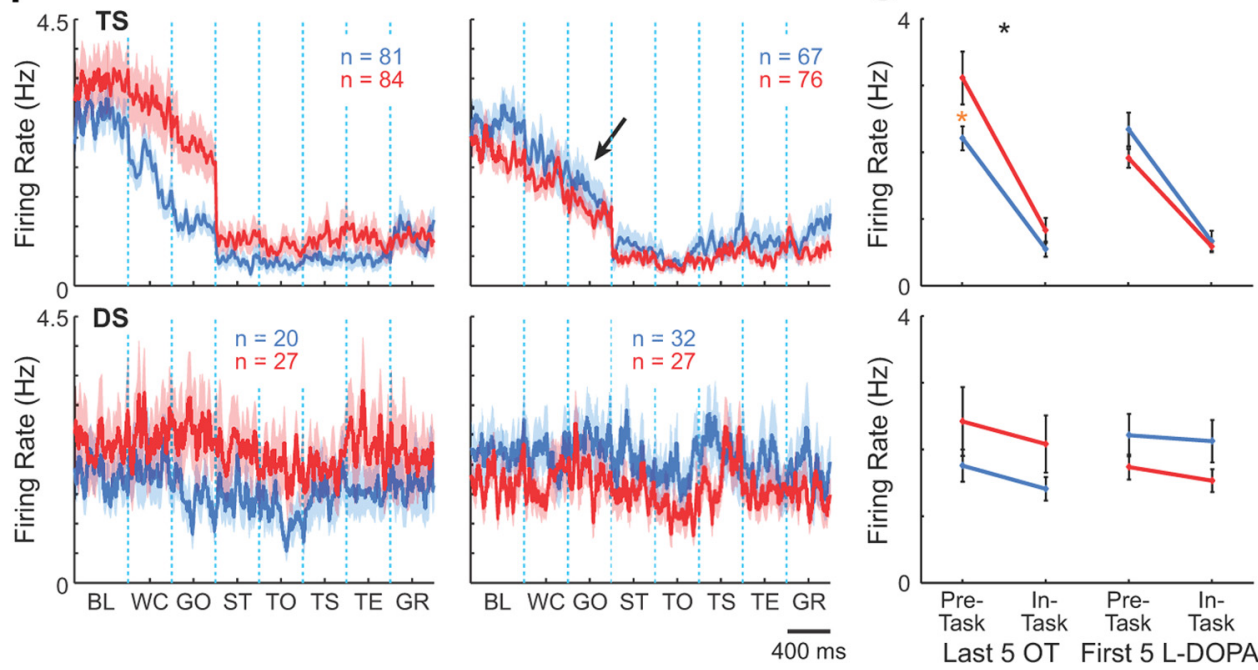

Figure 7. L-DOPA administration modifies activity of striatal projection neurons. $A$, Response accuracy (left), reaction times (middle), and running times (right) during last five overtraining (0T; light blue), saline (S; gray), and first five L-DOPA (light brown) sessions. Error bars indicate SEM. $\boldsymbol{B}, \boldsymbol{E}$, Ensemble activity of task-activated (B) and tonically task-suppressed (E) MSNs during the last five overtraining, saline, and first five L-DOPA sessions. Conventions are as in Figure 4. $\boldsymbol{C}, \boldsymbol{F}$, Raw firing rates of task-activated $(\boldsymbol{C})$ and task-suppressed $(\boldsymbol{F})$ MSNs in the control (blue) and dopamine-depleted (red) striatum, averaged across last five overtraining sessions (left) and first five L-DOPA sessions (right). L-DOPA treatment reduced the enhanced pre-task activity of tonically suppressed MSNs (TS; arrow) but did not affect the dynamically suppressed (DS) MSN population. D, G, Pre-task and in-task firing rates of task-activated (D), tonically suppressed (G, top), and dynamically suppressed ( $G$, bottom) MSNs, averaged over last five overtraining sessions and first five L-DOPA sessions. Asterisks indicate significant differences as in Figure $4 E$. BL, baseline; WC, warning click; GO, gate opening; $S T$, start; TO, tone onset; TS, turn start; TE, turn end; and GR, goal-reaching. 
A

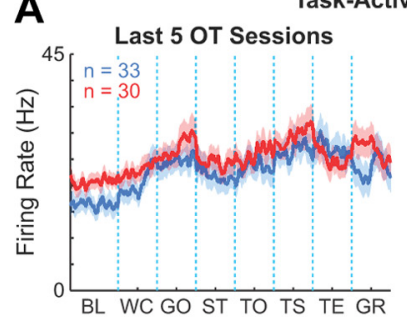

Task-Activated FSIs
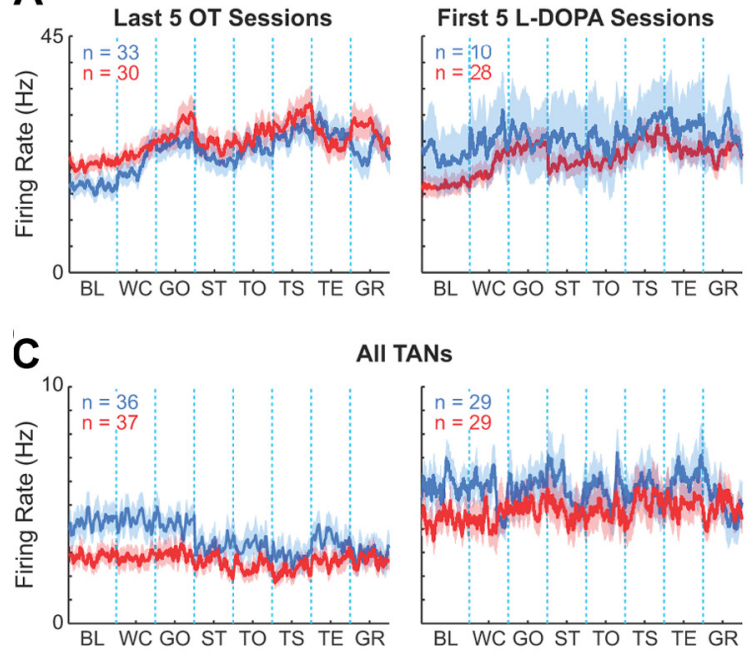

All TANs

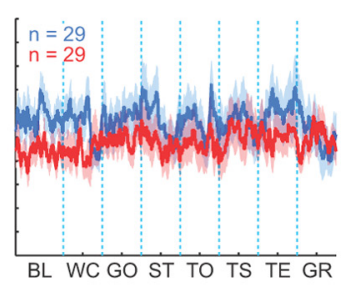

$4 \overline{00 \mathrm{~ms}}$
B

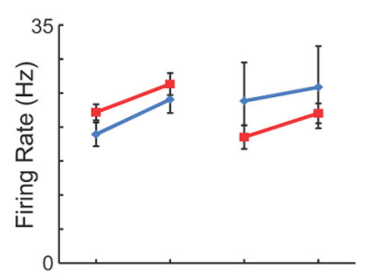

D

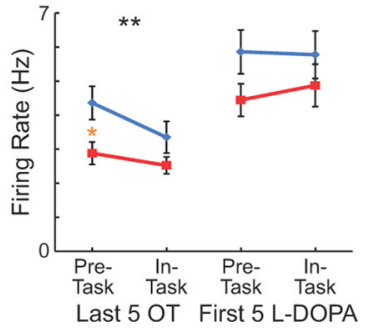

Figure 8. Differential effects of L-DOPA treatment on the activity of striatal interneuron populations. $A, C$, Raw firing rates of task-activated FSIs $(\boldsymbol{A})$ and all recorded TANs $(\boldsymbol{C})$ averaged over the last five overtraining sessions (left) and first five L-DOPA sessions (right). $\boldsymbol{B}, \boldsymbol{D}$, Mean pre- and in-task firing rates of task-activated FSI ensembles $(\boldsymbol{B})$ and all recorded TAN ensembles $(\boldsymbol{D})$. Asterisks indicate significant differences as in Figure 4E. BL, baseline; WC, warning click; $G 0$, gate opening; $S T$, start; $T 0$, tone onset; TS, turn start; TE, turn end; and GR, goal-reaching.

The population of TANs recorded during the L-DOPA treatment did exhibit significant increases in firing rates on the dopamine-depleted side, and their firing rates increased even on the control side (Fig. $8 C, D ; p<0.0001$ ). The pause response to task events exhibited by some TANs was not affected by L-DOPA administration on either side ( $p>0.3, \chi^{2}$ test).

\section{Discussion}

Our findings demonstrate that the behavior-related dynamics of striatal circuits are profoundly affected both by a loss of dopamine in the sensorimotor striatum and by subsequent L-DOPA therapy. These effects are not only selective for particular phases of task behavior, but are dependent also on the degree to which the task behaviors have been learned. Surprisingly, the task-bracketing pattern of activity that normally develops during learning in task-activated MSNs was not abolished by dopamine depletion. Yet this same activity pattern was obscured for the FSIs recorded simultaneously in the same dopamine-depleted region of the striatum. This contrast emphasizes the marked cell-type specificity of the effects of dopamine depletion on the sensorimotor striatum. Further, although this hallmark pattern of neuroplasticity was not blocked in the MSNs by prior dopamine depletion, the depletion did still affect them. The firing rates of the MSNs were elevated most prominently during the task periods in which they normally tended to fire: during the in-task period for the task-activated MSNs and during the pre-run period for the tonically suppressed MSNs. The effects of the dopamine depletion on the pre-movement task-time activity of tonically suppressed MSNs appeared to be learning-stage dependent, as they were expressed only as behavioral learning occurred. These findings provide a potential link between the normal learning-related dynamics of the nigrostriatal system and the deficits suffered in Parkinson's disease and related parkinsonian disorders.

The relative restorative effects of subsequent L-DOPA therapy on neuronal activity were equally selective. For the MSNs,
L-DOPA treatment diminished firing rates so that they matched control levels during the task period just before maze running. For the task-activated MSNs, L-DOPA treatment had additional effects, increasing firing rates particularly during periods of action initiation (around run-start) and termination (at goal-reaching). Strikingly, L-DOPA produced no detectable changes in FSI ensemble activity, even though their learning-related plasticity was blunted by the original dopamine depletion. Thus, the effects of dopamine depletion and dopamine restoration were celltype dependent, and these dopaminergic manipulations had contrasting effects on FSIs. These findings suggest that some of the network-level effects of dopamine depletion in the striatum remain vulnerable even after dopamine replacement therapy, and raise the possibility that non-dopamine-dependent control may be a promising target of further therapeutic development.

\section{Both task-activated and task-} suppressed striatal projection neurons are strongly affected by dopamine depletion and restoration but with different dynamics

Our findings support the division of MSNs in the sensorimotor striatum into a subpopulation of neurons that fire during task time and show marked plasticity in their task-related responses, and a second subpopulation of neurons that have relatively weak firing during the active task time but that do exhibit pre-task activity (Barnes et al., 2005). Such a division of striatal MSNs has been confirmed and extended in a number of studies (Kubota et al., 2009; Jin and Costa, 2010; Thorn et al., 2010; Barnes et al., 2011). Here we show that localized dopamine depletion in the sensorimotor striatum elevated firing in both sets of MSNs that we identified, the task-activated and task-suppressed subpopulations, but these elevations were most pronounced during different task periods. This result suggests that the effect of dopamine depletion may be to elevate the responsiveness of sets of inputs selectively targeting these two projection-neuron subpopulations. This conclusion is consistent with evidence from in vivo and in vitro studies indicating that dopamine depletion elevates the excitability of subsets of striatal neurons (Calabresi et al., 1993; Chen et al., 2001; Mallet et al., 2006). However, the observed effects on excitability were not expressed uniformly either across task time or across learning, suggesting that the effects of dopamine depletion could be dependent upon other processes, such as behaviorally shaped inputs and learning-dependent plasticity.

We could not directly identify many of the known MSN types, for example, direct and indirect pathway neurons or striosome and matrix neurons. Nonetheless, our findings suggest that the effects of dopamine depletion are exquisitely selective and depend on cell type, task demands, and learning-related network dynamics. A particularly interesting possibility is that decreased spike activity before maze running and increased responses around run start could be related to the efficacy of L-DOPA in facilitating action initiation, perhaps by reducing excessive activ- 
ity in "no-go" indirect pathway MSNs and by enhancing activity in "go" direct pathway MSNs. However, the rats actually had slightly longer reaction times after the L-DOPA treatment, not shorter ones. This lengthening could have been related to other potential effects of the L-DOPA, including motivational changes, a change in context, or even drowsiness (Andreu et al., 1999), masking other potential reaction time effects.

Our findings indicate that the disruption of striatal activity patterns that occurs following intrastriatal dopamine depletion emerges as animals learn new tasks. Our experimental design does not allow us entirely to exclude the possibility that these apparent learning-related effects may be due to progressive compensatory responses to dopamine depletion. We found, however, nearly identical patterns of effects in rats that began training after different postlesion intervals, with the only exception being the pre-trial baseline activity of tonically suppressed MSNs. This working hypothesis of a learning dependency of the depletion effect is compatible with the wealth of evidence that dopamine is a critical part of nigrostriatal learning circuits (Aosaki et al., 1994a; Centonze et al., 1999; Schultz, 2007; Stalnaker et al., 2012).

What makes the observation of special interest is that we did not find wholesale disruption of the learning-related plasticity in ensemble activity known to occur during T-maze learning. Remarkably, the task-bracketing activity pattern that forms normally among task-activated MSNs developed clearly in the dopamine-depleted striatum, indicating that dopaminedependent plasticity in the sensorimotor striatum may be responsible for only a subset of the learning-related changes in network activity patterns observed across learning. One possibility is that, because we depleted dopamine only locally in the sensorimotor striatum, dopamine released in nearby striatal sites may have diffused into the depleted zone (Rice and Cragg, 2008), allowing the pattern formation. Dopamine in non-striatal sites could have helped in shaping the relatively normal taskbracketing pattern. An interesting alternative is that nondopaminergic influences could be more important for this ensemble-level plasticity in the sensorimotor striatum.

\section{Dopamine depletion produces loss of task-related patterning of striatal FSI spike activity}

The fast-spiking inhibitory interneurons of the striatum, thought to correspond mainly to the parvalbumin-containing GABAergic interneurons (Kawaguchi, 1993), provide feedforward inhibitory signals to striatal MSNs through excitatory corticostriatal projections to these interneurons. Previous studies (Bennett and Bolam, 1994; Parthasarathy and Graybiel, 1997; Berke, 2011; Howe et al., 2011) point to these striatal FSIs as key integrators of striatal circuit function, and dopamine depletion has been shown severely to affect their firing properties in vitro (Salin et al., 2009; Gittis et al., 2011). Here we demonstrate that learning-related patterning of FSI activity, clearly observed in simultaneous recordings made on the intact side, was severely disrupted on the dopamine-depleted side.

This deficit in FSI plasticity is striking considering the clear beginning-and-end patterning of spike activity shown by the simultaneously recorded task-activated MSNs. The contrast extends to task-time patterning: the major depletion-induced abnormalities in firing of the task-suppressed ensembles occurred during the pre-start periods, the periods not affected for the FSI ensembles. Thus neither the firing patterns of the taskactivated MSNs nor those of the task-suppressed MSNs could be predicted by the marked changes in FSI ensemble activity. This result indicates that there is not tight coupling between the plas- ticity in firing patterns of FSIs and MSNs, a result supported by previous studies (Salin et al., 2009; Lansink et al., 2010; Berke, 2011).

Our recordings also suggest a sharp contrast between the responsiveness of FSIs and MSNs to restoration of intrastriatal dopamine levels. Some of the changes in MSN firing induced by the original dopamine depletion were reversed by L-DOPA treatment, but we saw no trend for restoration of the task-bracketing activity in the relatively small sample of FSIs that we were able to record at that late stage of the chronic recordings.

The effect of dopamine depletion on TANs contrasted to that of both the MSNs and FSIs in several ways. TANs formed the only cell population characterized by decreased firing rates as a consequence of dopamine depletion; this effect was not task-time dependent; and it was strongest during the acquisition phase of training rather than later. In at least some of the putative TANs, a typical pause to salient rewarding events was found (Fig. $3 E$ ) as previously observed in primates (Apicella, 2007). However, in primates, the dopamine depletion diminishes cue-related pause responses in most TANs (Aosaki et al., 1994a), whereas here, in our relatively small sample, we found pause responses in both the control and dopamine-depleted striatum, perhaps due to other inputs including those from the thalamus (Lacey et al., 2007; Goldberg and Reynolds, 2011; Threlfell et al., 2012).

Our findings suggest a startling level of selectivity in subcircuit dysfunction in the striatum following dopamine depletion, and a comparably striking selectivity in the restorative effects of L-DOPA treatment. This inventory of differential effects should provide valuable leads to developing equally selective therapeutic approaches to Parkinson's disease and related dopaminedepletion disorders.

\section{References}

Andreu N, Chalé JJ, Senard JM, Thalamas C, Montastruc JL, Rascol O (1999) L-Dopa-induced sedation: a double-blind cross-over controlled study versus triazolam and placebo in healthy volunteers. Clin Neuropharmacol 22:15-23. CrossRef Medline

Aosaki T, Graybiel AM, Kimura M (1994a) Effects of the nigrostriatal dopamine system on acquired neural responses in the striatum of behaving monkeys. Science 265:412-415. CrossRef Medline

Aosaki T, Tsubokawa H, Ishida A, Watanabe K, Graybiel AM, Kimura M (1994b) Responses of tonically active neurons in the primate's striatum undergo systematic changes during behavioral sensorimotor conditioning. J Neurosci 14:3969-3984. Medline

Apicella P (2007) Leading tonically active neurons of the striatum from reward detection to context recognition. Trends Neurosci 30:299-306. CrossRef Medline

Barnes TD, Mao JB, Hu D, Kubota Y, Dreyer AA, Stamoulis C, Brown EN, Graybiel AM (2011) Advance cueing produces enhanced actionboundary patterns of spike activity in the sensorimotor striatum. J Neurophysiol 105:1861-1878. CrossRef Medline

Barnes TD, Kubota Y, Hu D, Jin DZ, Graybiel AM (2005) Activity of striatal neurons reflects dynamic encoding and recoding of procedural memories. Nature 437:1158-1161. CrossRef Medline

Bennett BD, Bolam JP (1994) Synaptic input and output of parvalbuminimmunoreactive neurons in the neostriatum of the rat. Neuroscience 62:707-719. CrossRef Medline

Berke JD (2011) Functional properties of striatal fast-spiking interneurons. Front Syst Neurosci 5:45. Medline

Braak H, Braak E (2000) Pathoanatomy of Parkinson's disease. J Neurol 247 [Suppl 2]:II3-10. Medline

Brown P (2007) Abnormal oscillatory synchronisation in the motor system leads to impaired movement. Curr Opin Neurobiol 17:656-664. CrossRef Medline

Calabresi P, Mercuri NB, Sancesario G, Bernardi G (1993) Electrophysiology of dopamine-denervated striatal neurons. Implications for Parkinson's disease. Brain 116:433-452. CrossRef Medline

Cameron IG, Watanabe M, Pari G, Munoz DP (2010) Executive impair- 
ment in Parkinson's disease: response automaticity and task switching. Neuropsychologia 48:1948-1957. CrossRef Medline

Centonze D, Gubellini P, Picconi B, Calabresi P, Giacomini P, Bernardi G (1999) Unilateral dopamine denervation blocks corticostriatal LTP. J Neurophysiol 82:3575-3579. Medline

Chen MT, Morales M, Woodward DJ, Hoffer BJ, Janak PH (2001) In vivo extracellular recording of striatal neurons in the awake rat following unilateral 6-hydroxydopamine lesions. Exp Neurol 171:72-83. CrossRef Medline

Clark JJ, Sandberg SG, Wanat MJ, Gan JO, Horne EA, Hart AS, Akers CA, Parker JG, Willuhn I, Martinez V, Evans SB, Stella N, Phillips PE (2010) Chronic microsensors for longitudinal, subsecond dopamine detection in behaving animals. Nat Methods 7:126-129. CrossRef Medline

Cools R, Barker RA, Sahakian BJ, Robbins TW (2001) Mechanisms of cognitive set flexibility in Parkinson's disease. Brain 124:2503-2512. CrossRef Medline

Day M, Wang Z, Ding J, An X, Ingham CA, Shering AF, Wokosin D, Ilijic E, Sun Z, Sampson AR, Mugnaini E, Deutch AY, Sesack SR, Arbuthnott GW, Surmeier DJ (2006) Selective elimination of glutamatergic synapses on striatopallidal neurons in Parkinson disease models. Nat Neurosci 9:251259. CrossRef Medline

Emondi AA, Rebrik SP, Kurgansky AV, Miller KD (2004) Tracking neurons recorded from tetrodes across time. J Neurosci Methods 135:95-105. CrossRef Medline

Faure A, Haberland U, Condé F, El Massioui N (2005) Lesion to the nigrostriatal dopamine system disrupts stimulus-response habit formation. J Neurosci 25:2771-2780. CrossRef Medline

Gerfen CR, Surmeier DJ (2011) Modulation of striatal projection systems by dopamine. Annu Rev Neurosci 34:441-466. CrossRef Medline

Gittis AH, Hang GB, LaDow ES, Shoenfeld LR, Atallah BV, Finkbeiner S, Kreitzer AC (2011) Rapid target-specific remodeling of fast-spiking inhibitory circuits after loss of dopamine. Neuron 71:858-868. CrossRef Medline

Goldberg JA, Reynolds JN (2011) Spontaneous firing and evoked pauses in the tonically active cholinergic interneurons of the striatum. Neuroscience 198:27-43. CrossRef Medline

Henderson JM, Carpenter K, Cartwright H, Halliday GM (2000) Degeneration of the centre median-parafascicular complex in Parkinson's disease. Ann Neurol 47:345-352. CrossRef Medline

Howe MW, Atallah HE, McCool A, Gibson DJ, Graybiel AM (2011) Habit learning is associated with major shifts in frequencies of oscillatory activity and synchronized spike firing in striatum. Proc Natl Acad Sci U S A 108:16801-16806. CrossRef Medline

Ingham CA, Hood SH, Arbuthnott GW (1989) Spine density on neostriatal neurones changes with 6-hydroxydopamine lesions and with age. Brain Res 503:334-338. CrossRef Medline

Jin X, Costa RM (2010) Start/stop signals emerge in nigrostriatal circuits during sequence learning. Nature 466:457-462. CrossRef Medline

Jog MS, Connolly CI, Kubota Y, Iyengar DR, Garrido L, Harlan R, Graybiel AM (2002) Tetrode technology: advances in implantable hardware, neuroimaging, and data analysis techniques. J Neurosci Methods 117: 141-152. CrossRef Medline
Jog MS, Kubota Y, Connolly CI, Hillegaart V, Graybiel AM (1999) Building neural representations of habits. Science 286:1745-1749. CrossRef Medline

Kawaguchi Y (1993) Physiological, morphological, and histochemical characterization of three classes of interneurons in rat neostriatum. J Neurosci 13:4908-4923. Medline

Keller RW Jr, Kuhr WG, Wightman RM, Zigmond MJ (1988) The effect of L-dopa on in vivo dopamine release from nigrostriatal bundle neurons. Brain Res 447:191-194. CrossRef Medline

Kubota Y, Liu J, Hu D, DeCoteau WE, Eden UT, Smith AC, Graybiel AM (2009) Stable encoding of task structure coexists with flexible coding of task events in sensorimotor striatum. J Neurophysiol 102:2142-2160. CrossRef Medline

Lacey CJ, Bolam JP, Magill PJ (2007) Novel and distinct operational principles of intralaminar thalamic neurons and their striatal projections. J Neurosci 27:4374-4384. CrossRef Medline

Lansink CS, Goltstein PM, Lankelma JV, Pennartz CM (2010) Fast-spiking interneurons of the rat ventral striatum: temporal coordination of activity with principal cells and responsiveness to reward. Eur J Neurosci 32:494508. CrossRef Medline

Lemaire N, Hernandez LF, Hu D, Kubota Y, Howe MW, Graybiel AM (2012) Effects of dopamine depletion on LFP oscillations in striatum are taskand learning-dependent and selectively reversed by L-DOPA. Proc Natl Acad Sci U S A 109:18126-18131. CrossRef Medline

Mallet N, Ballion B, Le Moine C, Gonon F (2006) Cortical inputs and GABA interneurons imbalance projection neurons in the striatum of parkinsonian rats. J Neurosci 26:3875-3884. CrossRef Medline

Parthasarathy HB, Graybiel AM (1997) Cortically driven immediate-early gene expression reflects modular influence of sensorimotor cortex on identified striatal neurons in the squirrel monkey. J Neurosci 17:24772491. Medline

Picconi B, Piccoli G, Calabresi P (2012) Synaptic dysfunction in Parkinson's disease. Adv Exp Med Biol 970:553-572. CrossRef Medline

Rice ME, Cragg SJ (2008) Dopamine spillover after quantal release: rethinking dopamine transmission in the nigrostriatal pathway. Brain Res Rev 58:303-313. CrossRef Medline

Salin P, López IP, Kachidian P, Barroso-Chinea P, Rico AJ, Gómez-Bautista V, Coulon P, Kerkerian-Le Goff L, Lanciego JL (2009) Changes to interneuron-driven striatal microcircuits in a rat model of Parkinson's disease. Neurobiol Dis 34:545-552. CrossRef Medline

Schultz W (2007) Multiple dopamine functions at different time courses. Annu Rev Neurosci 30:259-288. CrossRef Medline

Stalnaker TA, Calhoon GG, Ogawa M, Roesch MR, Schoenbaum G (2012) Reward prediction error signaling in posterior dorsomedial striatum is action specific. J Neurosci 32:10296-10305. CrossRef Medline

Thorn CA, Atallah H, Howe M, Graybiel AM (2010) Differential dynamics of activity changes in dorsolateral and dorsomedial striatal loops during learning. Neuron 66:781-795. CrossRef Medline

Threlfell S, Lalic T, Platt NJ, Jennings KA, Deisseroth K, Cragg SJ (2012) Striatal dopamine release is triggered by synchronized activity in cholinergic interneurons. Neuron 75:58-64. CrossRef Medline 